\title{
Coriolis flowmeters: a review of developments over the past 20 years, and an assessment of the state of the art and likely future directions
}

Tao Wang , KROHNE Ltd., 34-38 Rutherford Drive, Wellingborough, NN8 6AE, U.K.

Roger Baker, University of Cambridge, 17 Charles Babbage Road, CB3 OFS, U.K.

\section{Abstract}

This paper starts from a brief revisit of key early published work so that an overview of modern Coriolis flowmeters can be provided based on a historical background. The paper, then, focuses on providing an updated review of Coriolis flow measurement technology over the past 20 years. Published research work and industrial Coriolis flowmeter design are both reviewed in details. It is the intention of this paper to provide a comprehensive review study of all important topics in the subject, which include interesting theoretical and experimental studies and innovative industrial developments and applications. The advances in fundamental understanding and technology development are clearly identified. Future directions in various areas together with some open questions are also outlined.

\section{Highlights:}

- A brief revisit of key early published work is provided.

- An updated review over the past 20 years is presented.

- Published research work and industrial Coriolis flowmeter design are both reviewed.

- Advances in fundamental understanding \& technology development are identified.

- Future directions together with open questions are outlined.

\section{Keywords}

Coriolis flowmeter, Coriolis flow sensor, converter, mass flow measurement

\section{Introduction}

In a paper [1] entitled "Coriolis flowmeters: industrial practice and published information" the state of the art on Coriolis flowmeters was reviewed. Over the past two decades, flowmeters based on the Coriolis principle have become one of the most important areas of development in flow measurement. The significant development of Coriolis flow measurement technology has covered a number of technical aspects and is due to

\footnotetext{
*Corresponding author: t.wang@krohne.com, +44 (0) 1933408544
} 
advances in theoretical modelling, signal processing, computing power, and testing facilities, and most importantly due to the acceptance by various industries. The increasing acceptance and importance have been highlighted by some interesting market research studies. Based on a market analysis of various flow measurement technologies, one market study [2] forecast that the Corolis flowmeter market will overtake differential pressure flowmeters as the largest market by 2014. Another market study [3] also identified Coriolis flowmeters as one of the fastest growing flowmeter markets. The study covered more than 10 manufacturers actively developing the technology.

In responding to the fastest growing trend, it is the aim of this paper to provide an updated and most comprehensive review of all technical aspects in the development related to the Coriolis flow measurement technology. This goal has been achieved by looking into a number of interesting theoretical and experimental studies, such as the fundamental analytical and numerical models for the measuring principle, latest developments of advanced signal processing and control techniques, and many other aspects related to Coriolis flowmeters. This goal has also been achieved by examining innovative industrial developments and applications, such as the expansion of flow range into either ultra low or high flow rates and the enhanced capability to deal with gas entrainment.

In this paper we first revisit the historical background, having identified some additional early work which appears to be of significance. This provides us with a thorough understanding to the historical developments of modern Coriolis flowmeters. We then review published research followed by a review of the main trends in industrial Coriolis flowmeter design.

It should be noted that our focus in this review is on flow measurement while we recognise that Coriolis flowmeters are multivariable instruments. It is also worth noting that there were other solutions to mass flow measurement, such as the fuel flow transmitter (see [4] for a description), the design of which made use of the torque created by angular momentum change. It probably suffered, in an age when mechanical precision is being displaced by solid state, from being a mechanical rotating device. 


\section{Review of published papers and key patents}

\subsection{Key early papers and patents}

In 1835 Gustave-Gaspard Coriolis published a paper, On the Equations of Relative Motion of Systems of Bodies, showing that a supplementary inertial force acts on a moving body in a rotating frame of reference [5], which became known as the "Coriolis force".

Kollsman [6] was, possibly, the first to describe a flowmeter, Figure 1, using the Coriolis principle in a patent published ${ }^{\dagger}$ on 8 July 1952. In his description, a motor was used to drive an impeller into rotation with interaction to the incoming fluid flow and a separate rotor was employed to sense force or torque imparted by the accelerated flow. Although Kollsman did not mention "Coriolis", the invention appears to make use of it.

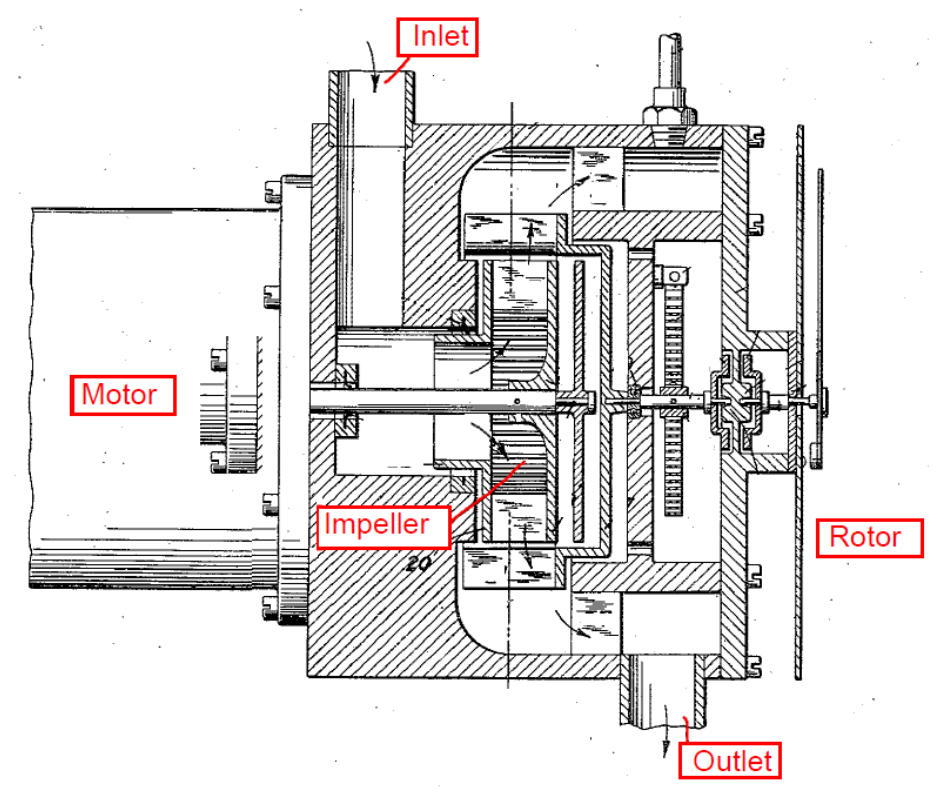

Figure 1 Kollsman [6] described an Apparatus for Measuring Weight Flow of Fluids in his patent (the patent filing date was 28 February 1946 in US)

${ }^{\dagger}$ On 15 March 2001 [7], the United States Patent and Trademark Office (USPTO) published its first set of patent applications before a patent was granted (or issued). This was regarded as "one of the most fundamentally significant changes to the U.S. patent system in over 100 years" because US patent applications were previously held in confidence until a patent was granted. Publishing applications before a patent is granted has some important benefits, which has been used by other major patent offices worldwide. Therefore, in this paper, we prefer to use publications of patent applications as the resource of previous literature instead of granted patents. Consequently, when we refer to a patent it means a publication of its application and it does not necessarily mean a granted patent. Thus, "publication number" and "publication date" are used for citation instead of "patent number" and "issue date". However, for US patents published before 2001, the publication number is the same as the patent number while the publication date is also the same as the issue date. 
Li and Lee [8] described another flowmeter using the rotary principle and specifically applied the theory of the Coriolis force for mass flow measurement as shown in Figure 2.

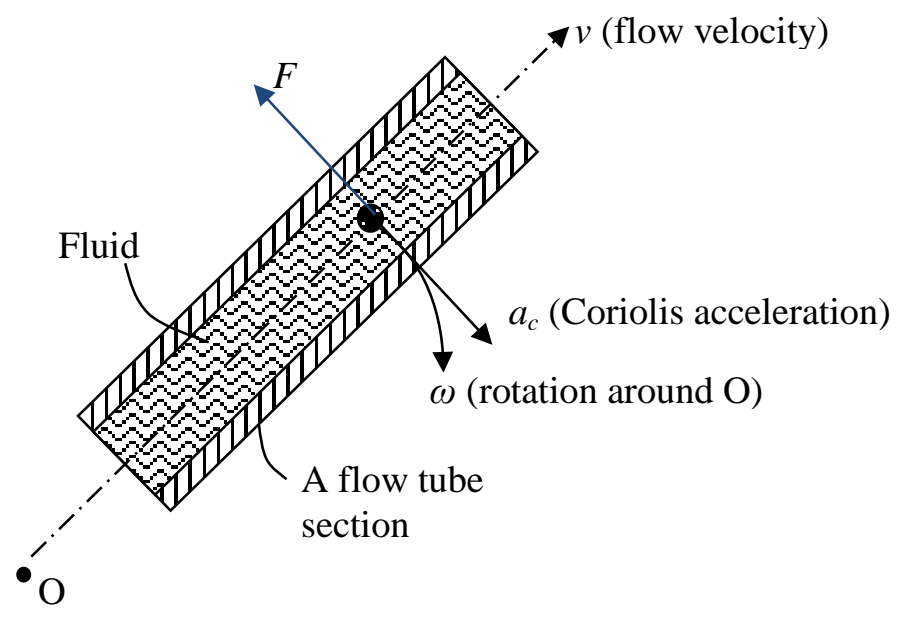

Figure 2 Flow measurement using the Coriolis principle (after [8], where $\omega$ is the angular velocity of the flow tube around the rotational centre $O, v$ is flow velocity, $a_{c}$ is Coriolis acceleration of a fluid element, $F$ is the "reactive" Coriolis force on the flow tube imparted by the flowing fluid)

Also Pearson [9] described a mass flowmeter with a curved conduit in a coil shape which could be driven either to rotation or oscillation, Figure 3. This is probably the earliest comment in the public domain to suggest oscillation (the patent was issued or published on 6 January 1953 though the patent filing date was 8 September 1949).

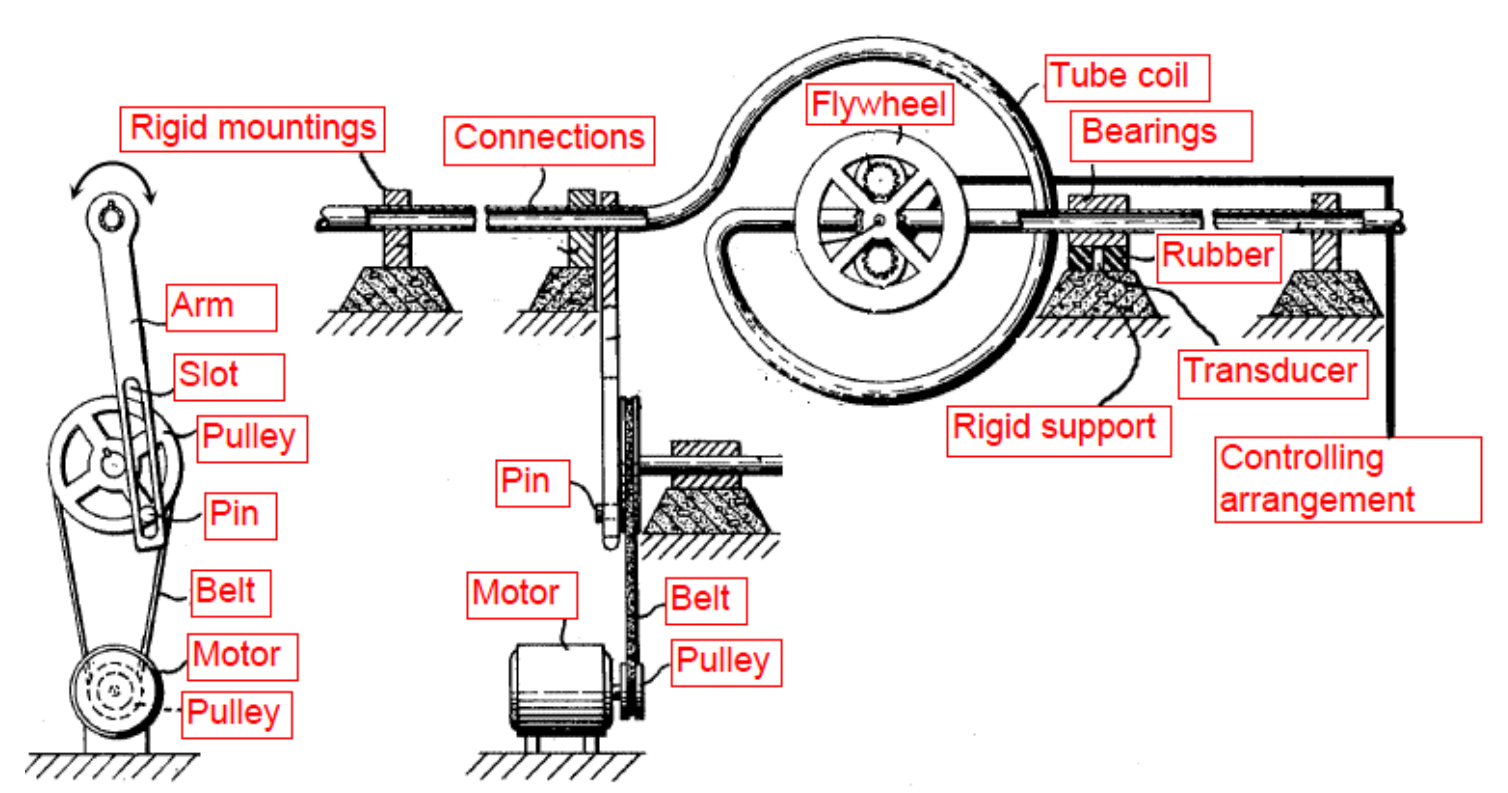

Figure 3 An early design of using a single flow tube in a coil shape where oscillation is an optional means for mass flow measurement [9]

In 1958 "Coriolis mass flowmeter" was used in the title of a patent by White [10]. 
Wiley et al. [11] described two designs using a straight conduit. In the first, a straight tube with an open end was used. In the second, in Figure 4, two in-line tubes were joined with a flexible coupling. Both inlet and outlet sections were driven into oscillation at resonance. An electromagnetic pickup was arranged on the outlet section to detect amplitude. The difference of the driving torques to maintain inlet and outlet in-phase was used as a means to measure mass flow rate.

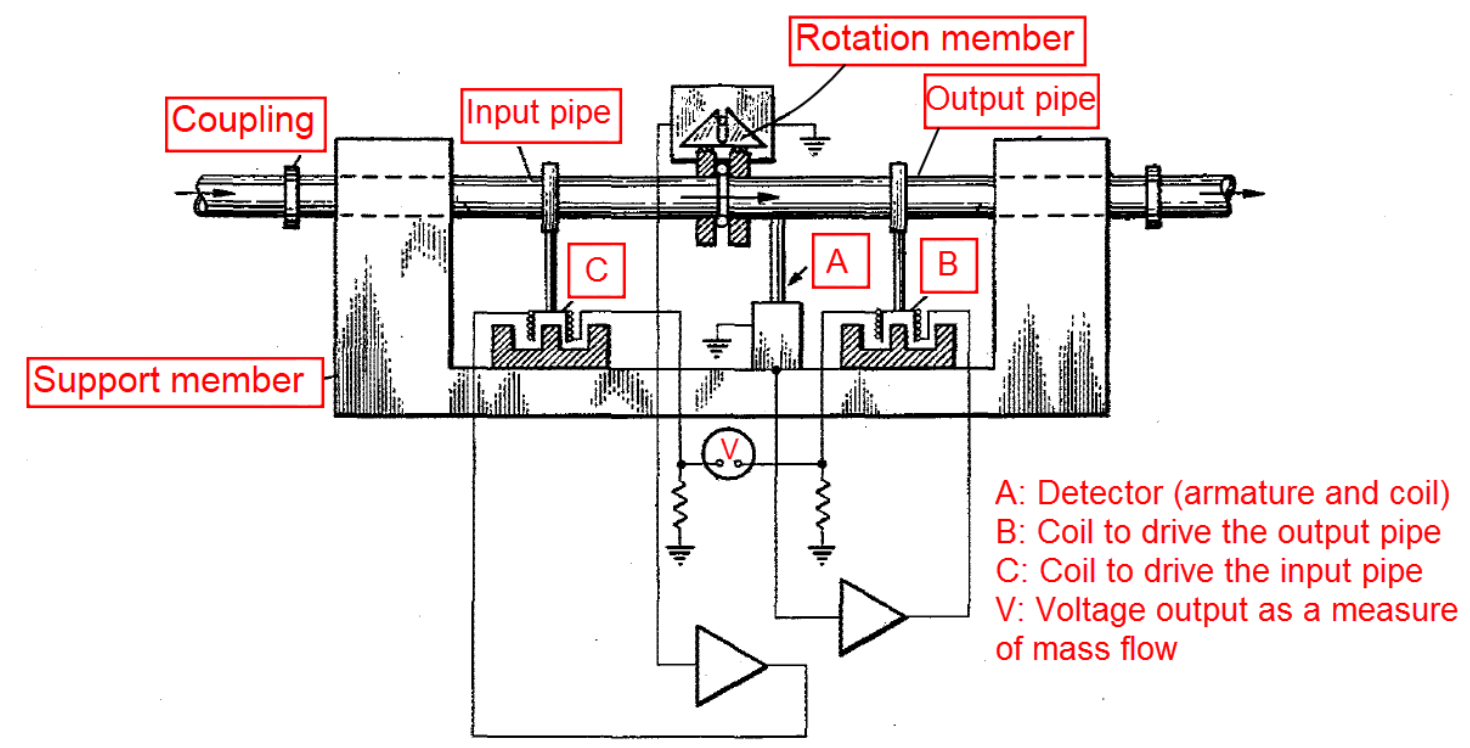

Figure 4 An early design using a single straight-tube configuration [11]

Sipin [12] described two designs of a straight tube mass flowmeter. In the first, the tube was oscillated by a motor and cam, and flow measurement was obtained using strain gauges or a torque motor. In the second, an electromagnetic driver oscillated the tube and two magnetic pickups detected motion on inlet and outlet tubes. Sipin observed that "due to mass flow the inlet bellows will tend to lag the vibratory motion and the outlet bellows will tend to lead" and that "the differential motion .... provide(d) an indication of mass flow." However, the Coriolis equation was not mentioned.

Sipin [13] also described a mass flowmeter where a bent tube was used as the measuring section. He commented that shallower or larger angle of bends than 90 degrees could be used.

Chemical and Engineering News, published by American Chemical Association, in December 1977 [14] described a "gyroscopic/Coriolis mass flowmeter" where the mass flow rate was a function of pipe geometry constants and the time interval between two motion sensors on the flow tube. Smith [15] showed such a Coriolis flowmeter with a U- 
shaped tube, Figure 5. He used a simple theoretical model to relate mass flow rate, $Q$, to time delay, $\Delta t$, between inlet and outlet motion sensors

$$
Q=\frac{K_{S} L}{8 r^{2}} \Delta t
$$

where $K_{S}$ is a spring constant, $L$ is length of the outlet leg , $r$ is inlet or outlet legs' distance to the central axis $\mathrm{O}-\mathrm{O}$.

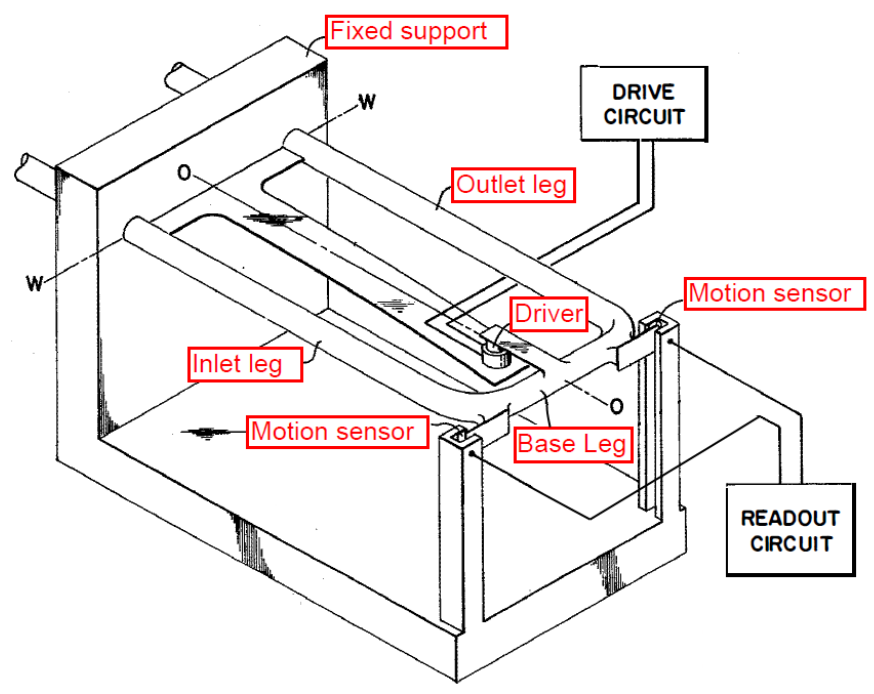

Figure 5 Mass flow rate was related to time delay between two motion sensors using a simplified theoretical model on a bent-tube Coriolis flowmeter [15]

In previous developments, force or torque created by mass flow was directly sensed to provide a measure of flow. However, Coriolis force is generally small and direct measurement of it cannot provide sufficient accuracy for flow measurement. In previous developments, difference or phase shift between inlet and outlet motion signals was also used. However, phase shift depends on the driving frequency unlike time delay. The employment of time delay overcame these problems and it provided a very useful basis for subsequent modern developments.

Cox and Gonzalez [16] described a flowmeter using a pair of U-shaped tube loops as shown in Figure 6. They clearly identified the advantage of using two identical vibrating loops against each other by stating that "if two U-shaped tubes are arranged in the shape of a tuning fork, much less power is needed to oscillate the two tubes at their natural frequency than would be required to oscillate one $U$-shaped tube alone“. Although the functionality of balancing or noise escaping was not specifically mentioned for utilizing two identical tube loops, their comment of less power might have implied it. In order to sense 
motion, they suggested using an optical means instead of magnetic pickups or strain gauges. It was also stated that "phase shift is proportional to the Coriolis force couple".

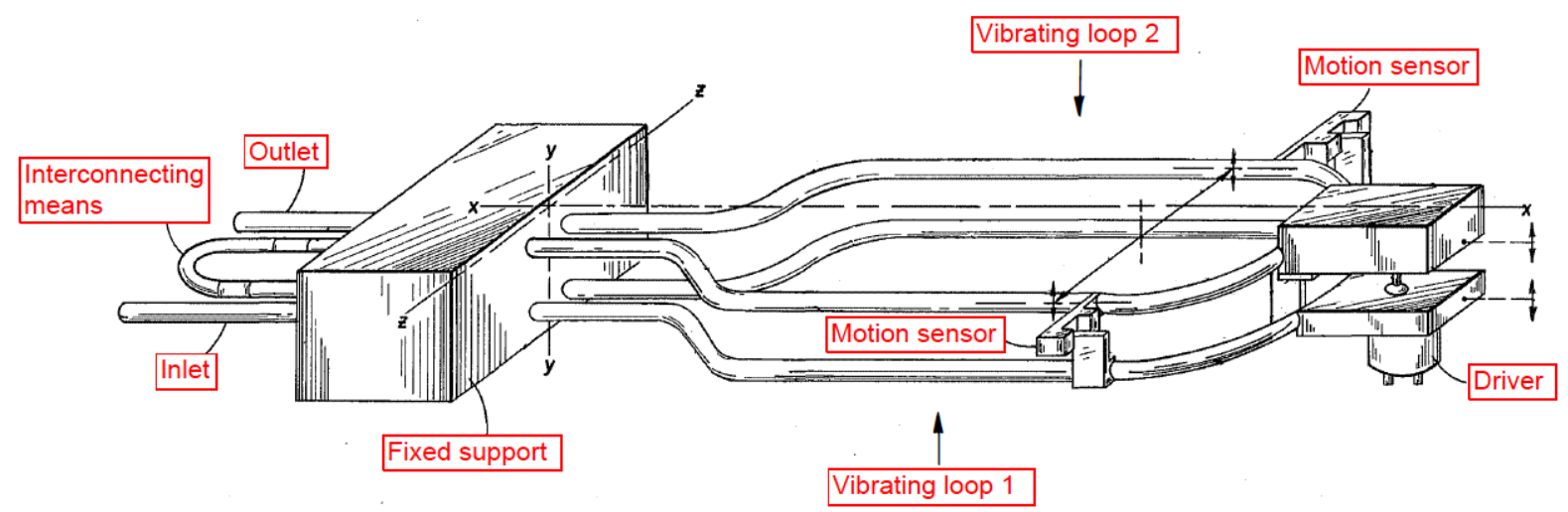

Figure 6 An early design of using a single flow-path bent-tube with dual-loop configuration [16]

Langdon [17] described a device to measure mass flow using surface vibration (or "travelling flexure wave" as used in his patent publication), which can be regarded as a "shell-mode" Coriolis flowmeter in comparison with other "beam-mode" flowmeters. Previous vibratory beam-mode Coriolis flowmeters relied upon bending of the whole flow tube. However, in a shell-mode Coriolis flowmeter there is no overall bending for the flow tube, only some surface areas experience local "shell" bending, so that the cross-section of the tube deforms. Langdon also described a particularly interesting aspect of his invention using longitudinal fluid flow along a tube where an internal vane was held at one end and driven into vibration as shown in Figure 7. The time difference between the signal outputs of two piezoelectric transducers, attached to the vane, provided an indication of the mass flow rate. 


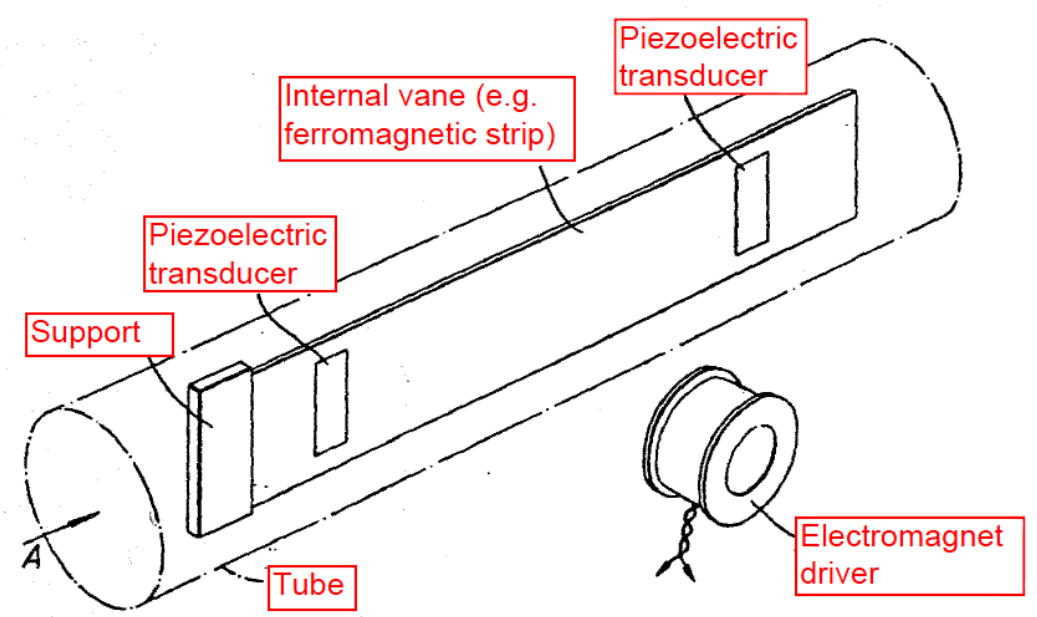

Figure 7 A mass flowmeter design where only part of the flow conduit surface vibrates which may be termed as a "shell-mode" Coriolis flowmeter in comparison with traditional beam-mode Coriolis flowmeters [17]

Smith and Cage [18] described a parallel path Coriolis flowmeter where two U-shaped tubes formed two parallel flow paths as shown in Figure 8. Previous known developments seem to have used a single flow path and there were two typical designs. The first design used a single tube loop [9], while the other design used multiple (typically two) tube loops [16]. Smith and Cage commented on the advantages of using a new twin flow-path design: achieving higher flow rate with better sensitivity, dynamically balanced pair, better decoupling due to floating reference to each other, reduced overall meter size, and less pressure loss.

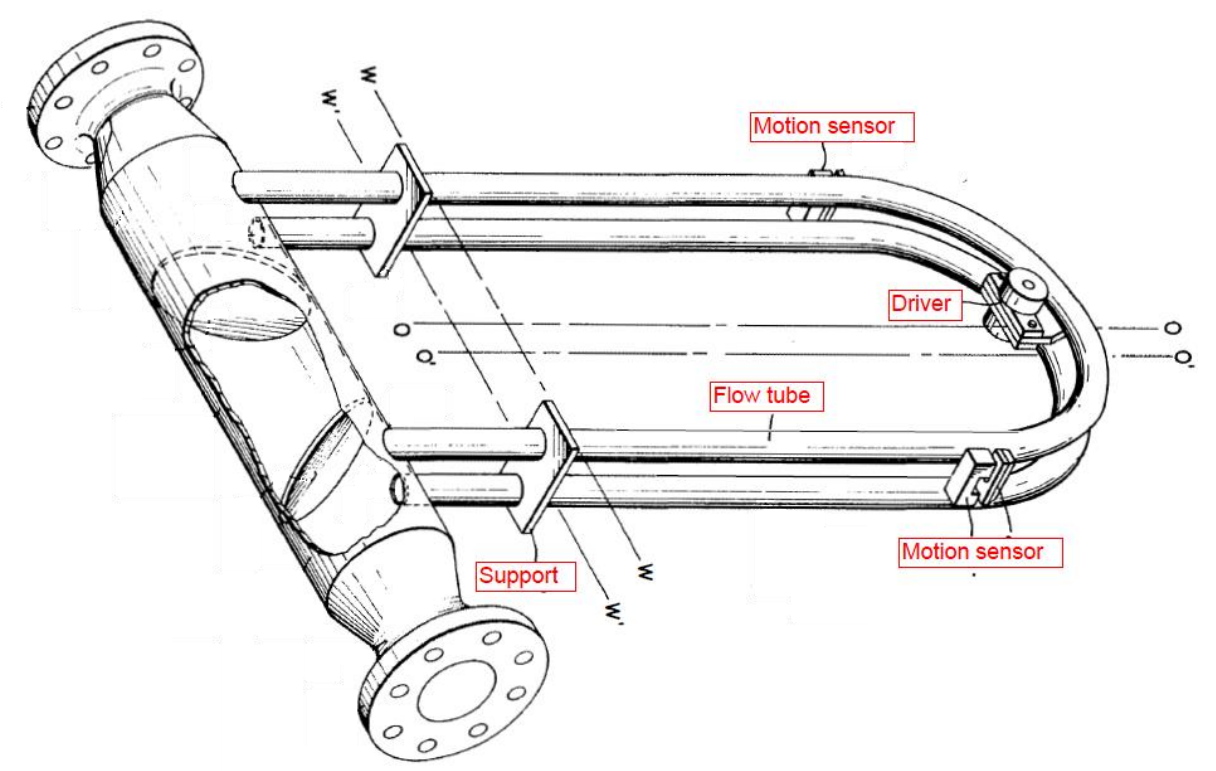

Figure 8 A typical twin bent-tube design [18] 
Mizerak [19] described a Coriolis flowmeter comprising a pair of straight parallel tubes as shown in Figure 9, at the inlet of which the fluid was divided equally into two straight tubes driven into vibration. At the outlet, the fluid recombined. Also for a twin tube design he noted that because the driving and sensing components are references to each other it will "help reduce common mode vibration noise and improve performance". He also suggested other advantages of such a design: ease of assembly, being compact in overall size, ease of installation, ease of scaling up and down in size, and less density sensitivity.

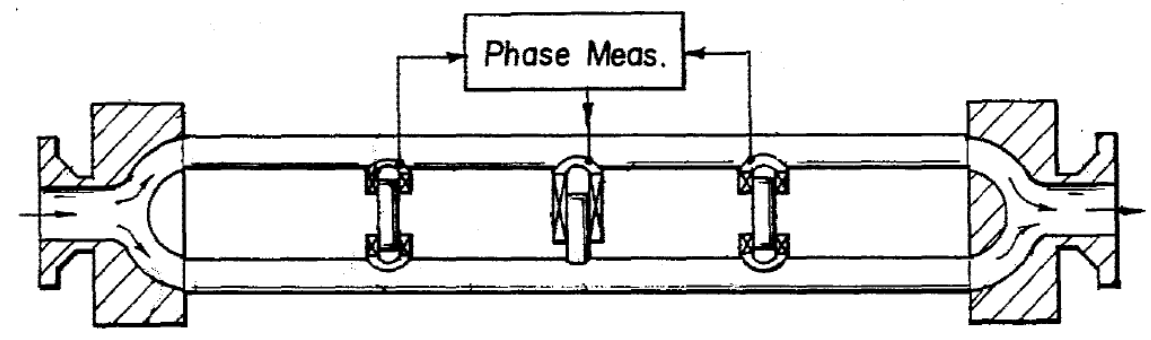

Figure 9 A typical twin straight-tube design [19]

In our review of early developments until 1986, we only selected some typical publications with a particular focus which had milestone importance and appeared to be the earliest according to their publication dates. These developments have created a useful and successful foundation for the development of modern Coriolis flowmeters.

\subsection{Technology overview of modern Coriolis flowmeters}

\subsubsection{Definition of key terms}

Coriolis flowmeters can be defined as a flow measuring device which relies on the interaction between the flowing material and its conveying structure to create Coriolis acceleration on the flowing material and to sense the reaction on the conveying structure.

This is a rather general definition and covers all potential technologies. Depending on the motion involved in the interaction between the flowing material and its conveying structure, one can classify Coriolis flowmeters into rotary or vibratory types. Depending on the flowing material being measured, one can classify Coriolis flowmeters into fluid or bulk solid applications. Depending on the structural feature of the interaction, whether the structure can be appropriately represented as a beam, one can classify Coriolis flowmeters further into beam-mode or shell-mode.

Thus, the modern Coriolis flowmeter for fluid flows can be defined as a flow measuring device which relies on the vibratory interaction between the fluid and its conveying pipe to 
create Coriolis acceleration on the fluid and to sense the reaction on the conveying pipe. The beam-mode Coriolis flowmeters rely on the tube vibration as a beam-bending structure (i.e. plane sections remain plane and have no or negligible cross-sectional deformation). They have sometimes been called "bending-mode" [20] or "beam-type" [21] Coriolis flowmeters. The shell-mode Coriolis flowmeters rely on the tube vibration as a shell-bending structure, and have sometimes been called "radial-mode" [20], "shell-type" [22], or "hoop-mode" [23] Coriolis flowmeters.

For a modern commercial Coriolis flowmeter, there are essentially two components: a flow sensor (primary device) and a flow converter (secondary device). The flow sensor is a mechanical assembly which consists of at least one oscillating flow tube, drive system, motion sensors, additional sensors, and supporting structure. The flow converter is an electronic control system which receives and processes signals from the flow sensor, provides drive to the flow sensor, and gives output of measured variables. In other publications, a flow sensor may be called "flow transducer" while a flow converter may be called "flow transmitter".

According to the configuration of the flow tube(s), one can make a further classification for a particular Coriolis flowmeter. One way of doing this is to use the number of flow paths, the shape of the flow tube, and the number of tube loops within each flow path. For example, the early development of [18] can be classified to twin (flow-path) bent-tube (single-loop) Coriolis flowmeter, while the development of [16] can be classified to single (flow-path) bent-tube multiple-loop Coriolis flowmeter. It should be noted that we understand there are many different naming possibilities to refer to different technologies. Our classification scheme as described in Appendix 5.1 is just a simple example we have found useful in this review.

\subsubsection{Basic operation}

The flow tube of a Coriolis flowmeter is vibrated at a resonant frequency, which is often called the drive or working frequency, $f_{d}$, or angular frequency, $\omega_{d}$, and the vibration mode may have a symmetric or anti-symmetric shape. When there is no flow the inlet and outlet portions are substantially in phase, but when there is flow, this drive mode is disturbed by Coriolis forces due to fluid-tube interaction. The Coriolis forces create a minute shape deformation at the drive frequency and this shape predominantly resembles 
a mode shape at a different resonant frequency, often called the Coriolis frequency $(\text { Coriolis mode })^{\ddagger}$. Because Coriolis forces on the inlet and outlet portions have similar magnitude but different direction with respect to the drive mode shape, phase shift or time delay is created between inlet and outlet motions. The following equation is generally used to measure mass flow rate:

$$
q_{m}=K \cdot\left(t_{d}-t_{0}\right)
$$

where $K$ is the flow calibration factor related to the sensitivity of flow measurement, $t_{d}$ is the time delay between two motion signals along the measuring section during flow and $t_{0}$ is the zero flow calibration time delay. Under ideal conditions, both $K$ and $t_{0}$ are constant and mass flow rate is linearly proportional to time delay. However, due to the fluidstructure interaction nature, the flow calibration factor is not only related to structural properties (e.g. Young's modulus) but also to fluid properties. Thus, all research and development work related to Coriolis flow measurement has been around this fundamental equation.

\subsubsection{Operational ranges, performance and general market information}

Since its early developments, Coriolis flowmeter technology has steadily grown into a major flow measurement technology. A recent market publication [2] forecast that Coriolis flowmeters would overtake differential pressure flowmeters to be the market leader. Coriolis flowmeters were traditionally operated in medium flow range with line size normally less than $100 \mathrm{~mm}$. Recently the range has seen extension to both low and high ranges by some major manufacturers [26]. If we use their scheme to define the flow measurement capacity, for example from 1 to $1,000 \mathrm{t} / \mathrm{h}$ nominal flow as the medium flow range, an interesting correlation between a nominal flow rate resulting in the same pressure drop and flow tube diameter can be observed as shown in Figure 10. The

‡ It is worth emphasizing that during the normal operation of a Coriolis flowmeter, only one vibration frequency or mode is excited to measure flow rate. The terminology of using either the Coriolis frequency or Coriolis mode is mainly from a mathematical point of view considering the connection between modal properties and frequency response characteristics. An analytical solution from the early work of Raszillier and Durst [24] showed the concept of modal superposition to the order of the first two modes (Eq. 4.31 of their paper). A numerical model from the recent work of Wang and Hussain [25] also quantitatively showed the contribution from other higher order modes (for example, Table 1 of their paper showed $1.5 \%$ contribution from a higher mode in addition to the main contributing "Coriolis mode"). 


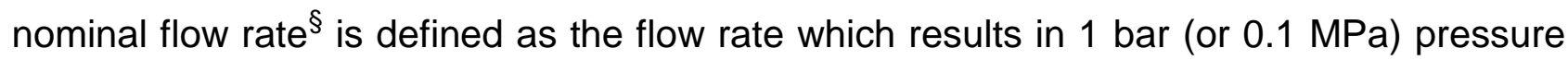
drop across the flowmeter with water for comparison, while the equivalent internal diameter is defined as the diameter of an equivalent pipe which results in the same internal area of the flow tube(s). For a single flow-path Coriolis flowmeter, the equivalent internal diameter is the flow tube diameter. However, for a multiple flow-path Coriolis flowmeter with $n$ equal tubes, the equivalent internal diameter is $\sqrt{n}$ multiplied by the flow tube diameter. In Figure 10, we included single straight-tube, twin straight-tube, single bent-tube and twin bent-tube Coriolis flowmeters from three major manufacturers. Using the definition of an equivalent diameter, we can compare them directly regardless of their flow sensor design. The linearly fitted empirical curve using a logarithmic scale is correct in terms of its magnitude (within $\pm 50 \%$ of the published nominal flow rate due to tube length variation and other minor pressure losses). This can provide a rough but useful estimation of line sizes and flow range. For example, the medium flow range from 1 to $1,000 \mathrm{t} / \mathrm{h}$ correlates to line sizes from 6 to $125 \mathrm{~mm}$, which is in general agreement with industrial practices. Thus, in order to extend to high flow range beyond $1,000 \mathrm{t} / \mathrm{h}$, line sizes are likely to be greater than $125 \mathrm{~mm}$.

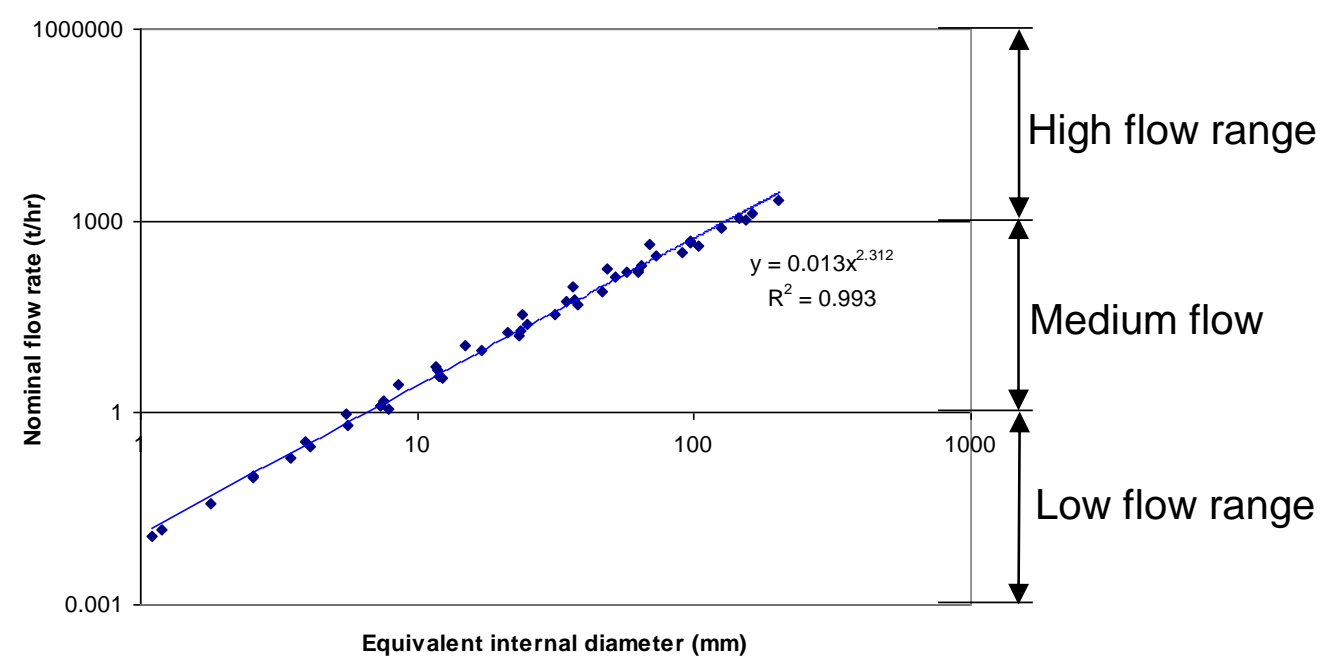

Figure 10 Nominal flow rate (for 1 bar pressure drop of water flow) vs. equivalent internal diameter of Coriolis flow meters from three manufacturers

\footnotetext{
$\S$ In a recent meeting of the ISO 10790 Working Group in which one of the authors participated, there was strong discussion among the participants regarding whether to use the term nominal flow rate. Although manufacturers usually provide a sizing program, the comparison of using such a sizing program between different flowmeters is not a straightforward task. The use of a nominal flow rate under the same reference condition, for example the nominal value under 1 bar pressure drop for water flow, can facilitate such a task.
} 
Using every three decades of mass flow rate to define a flow range, $1,000 \mathrm{t} / \mathrm{h}$ to $1,000,000 \mathrm{t} / \mathrm{h}$ may be termed as high flow range while $1 \mathrm{~kg} / \mathrm{h}$ to $1 \mathrm{t} / \mathrm{h}$ may be termed as low flow range. Interestingly, there are even smaller size Coriolis flowmeters commercially available. However, we cannot find published information on tube diameters and are not able to put them in Figure 10. Nevertheless, the smallest flowmeters from two typical manufacturers can offer nominal flow rate $150 \mathrm{~g} / \mathrm{h}$ [27] and $100 \mathrm{~g} / \mathrm{h}$ [28] respectively. Consequently, we may define the flow range between $1 \mathrm{~g} / \mathrm{h}$ and $1 \mathrm{~kg} / \mathrm{h}$ as the "very low flow range" and possibly $1 \mathrm{mg} / \mathrm{h}$ to $1 \mathrm{~g} / \mathrm{h}$ as the "ultra low flow range". It is worth noting that at these low flow ranges, water flows are typically laminar due to small Reynolds numbers and the empirical curve shown in Figure 10 based on turbulent flow data may be modified to cover these low flow ranges.

Performance of a Coriolis flowmeter is normally specified by the manufacturer using a base accuracy value and a zero stability value. The base accuracy value is defined as a percentage of the reading, while the zero stability value is normally specified by either a mass flow rate value or a percentage of a known nominal value. As reviewed by Baker [1], the maximum allowable errors or maximum permissible errors (MPE) were specified by the addition of the base accuracy and zero stability values, which resulted in a smooth (C1 continuity $^{* *}$ ) maximum error curve. Recently, some manufacturers started to use a different approach to define the maximum errors where the base accuracy value applies to flow rates greater than a specific flow rate and the zero stability value applies to lower flow rates. This specific flow rate is normally calculated as zero stability divided by the base accuracy value, which results in a non-smooth (CO continuity) maximum error curve. A comparison between these two curves is shown in Figure 11, and the difference is mostly noticeable within the low flow region.

** 1 continuity means that the first derivative of the curve exists and is continuous. 

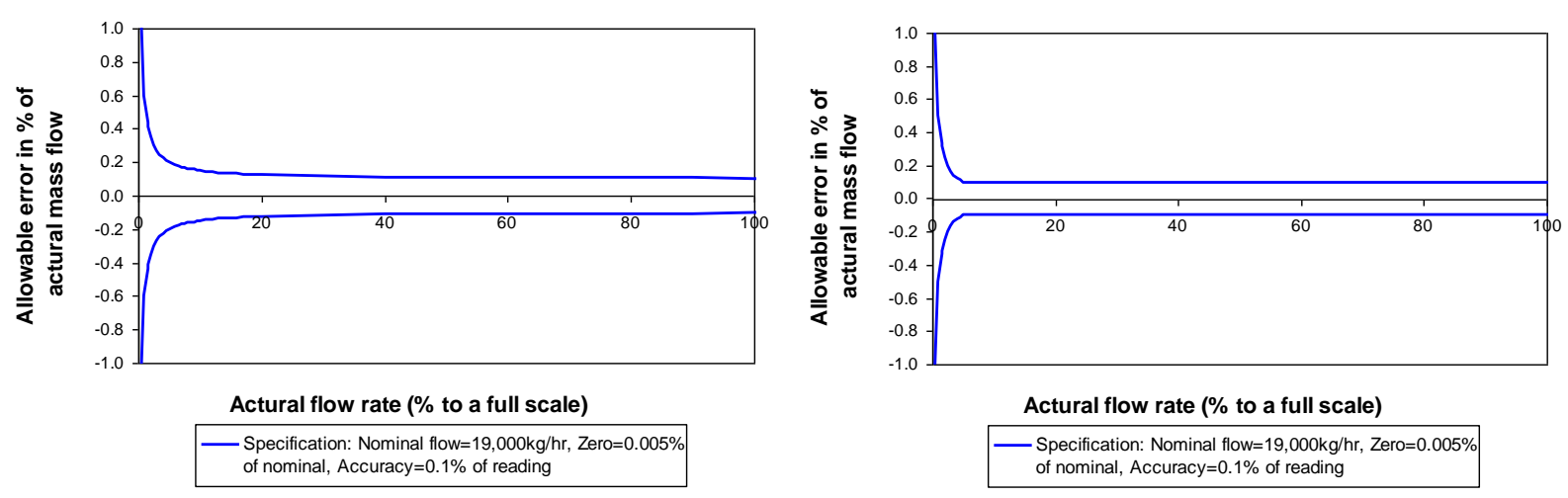

Figure 11 Comparison of two allowable error curves of mass flow measurement. The left is a smooth curve while the right is a non-smooth curve (the so-called flat specification)

With increased acceptance by the industry of Coriolis flowmeters, various international standards [29-32] have been developed to guide the use of Coriolis flowmeters for both liquid and gas applications. The latest version of ISO 10790 was published in 1999 and amended in 2003. Currently a writing group are working on the latest revision.

\subsection{Brief review of published research material}

\subsubsection{General reviews}

In a special issue of IEE Computing and Control Engineering a series of summaries of papers given at an Oxford seminar were introduced by Tombs [33]. Also a special issue of the Journal of Flow Measurement and Instrumentation [34] was dedicated to Coriolis flowmeters. The editors of it noted that an earlier issue (Volume 5(4) 1994 edited by H. Raszillier \& F. Durst) had identified four subjects in urgent need of improved understanding: the behaviour of the instrument in non-stationary flows, the influence of fluid compressibility, corrections in the measuring principle for high flow rates and the behaviour of meters in two-phase flow. They noted that there had been some work published on the first two topics with a reasonable gain in understanding, but they considered that the matter of high flow rates was not of great concern at that time, and that the problem of two-phase flow would take rather longer to solve. Anklin et al. [35] gave an updated review which has some useful explanations and descriptions of the flowmeters available.

\subsubsection{Analytical and numerical modelling for flow sensors}

As we have explained above, the Coriolis flowmeter measuring principle relies on interaction between a fluid and its conveying structure. For the theoretical understanding of fluid-structure interaction (FSI), there are a large number of dedicated publications, but 
many of them are not related to flow measurement applications. Païdoussis [36,37] presented and summarized various fundamental theories in two volumes of his book entitled Fluid - structure Interactions: Slender Structures and Axial Flow. He noted that virtually all research work on the dynamics of fluid-conveying pipes had been curiositydriven rather than application-driven. Nevertheless, some applications, including Coriolis flowmeters, had emerged since his basic work in the early 1990s. He also interestingly commented that "most engineering applications" related to one of his chapters "involve problems" and "it is therefore refreshing to have at least one application, which is wholly benign" - that was Coriolis flowmeters. Governing equations and solutions on fluid structure interaction for both beam-mode and shell-mode Coriolis flowmeters can be found in his book.

Hemp [38] described the physical characteristics of a vibrating flow tube as a steady flow interacting with the vibrational velocity and the interaction giving rise to a body force in the fluid. This body force causes a secondary vibration in the fluid and on its boundary. Using the principle of reciprocity, Hemp [38] described a weight vector method which can be used to study the effect of velocity distribution. The weight vector depends on two vibrational fields set up in the stationary fluid. In order to obtain the effect of velocity distribution, the fluid velocity field vector is multiplied by the weight vector and integrated over the entire volume of the fluid. Solution in conjunction with solid body vibration and boundary conditions is also needed. Two simple cases (e.g. a rigid U-shaped flow tube) were studied and the author suggested that extension to other more practical configurations was possible. In the second part of their weight vector theory work, Hemp and Hendry [39] suggested that viscosity can be allowed for in the vibrational motion. Viscosity brings an additional contribution to the secondary vibration [38]. Thus, in order to consider this, an additional integration was included in the weight vector method by providing a new weight vector for the surface vorticity. The authors commented that it is difficult to know under what conditions viscosity cannot be neglected because it depends on both flow velocity distribution and flow tube geometry. However, in precise calculations of flowmeter sensitivity using the weight vector theory, it might be necessary to include both the volume and surface weight vectors.

Hemp [40] demonstrated the weight vector approach to calculate the flowmeter sensitivity for a straight flow tube with free ends and fully developed flow. The analytical expression for phase difference is dimensionally the same as the one obtained by 
Raszillier and Durst [24] for a straight flow tube with clamped ends. The Coriolis flowmeter also lends itself to the use of sophisticated computer models which take in the fine detail of the construction as well as allowing for fluid behaviour, compressibility, homogeneity and other features. Hulbert et al. [41] discussed a finite element numerical analysis of Coriolis flowmeters, and compared it with experiment. They noted that axial tension terms were important. Keita [42] used a multipurpose finite element code with fluid-structure interaction to obtain the characteristics of the Coriolis flowmeter in the form of a straight pipe with clamped ends. His results compared well with previous experimental and theoretical values. The paper suggested that the procedures were far from straightforward as yet. Cunningham and Hensley [43] used IMAT and Matlab for Coriolis flowmeter design. The new tools developed by a manufacturer have made use of these and other techniques to provide sufficient capability for the increasingly stringent design requirements and additional analysis.

Kutin and Bajsić [44] noted that ideally there should be independence between mass flow rate and density measurement in ideal characteristics. [24] obtained this ideal characteristic by assuming a second order constraint condition on the fluid velocity i.e. velocity squared is far less than the critical velocity squared (Eq.4.19 of [24]. However, when the fluid velocity approaches the critical velocity, the so-called stability boundary effect needs to be considered. Thus, the omitted second order should be included when approaching the critical velocity. Kutin and Bajsić [44] assumed a fourth order constraint condition on the fluid velocity instead. Using the Galerkin method, they presented a solution of the governing equation for a straight flow tube and noted that the largest influence would come from the centrifugal term in the governing equation. The authors did not appear to give typical values for common designs.

Kutin and Bajsić [45] extended their early work on the stability boundary effect and further studied the non-ideal effects of added masses, damping, excitation and axial force. Using the Galerkin method, analytical expressions based on a linear superposition of a number of modal functions were provided for both the natural frequency and time delay. They concluded that added masses can also affect the measuring characteristics so that density and flow measurements may depend on each other. With regards to damping, they suggested that its influence can be neglected because the tube conveying incompressible fluid is normally lightly damped. They also commented that the axial force only affects the 
flowmeter's sensitivity, but the effects on density and mass flow measurements are independent.

Since Stack et al. [46] introduced a finite element method to solve the governing equations for the fluid-conveying Timoshenko beam, the numerical method to model flow sensors has become an important development tool. Stack et al. [46] described three matrices, mass, stiffness and damping, in the finite element formulation. A general purpose finite element code MSC/NASTRAN was used to solve a complex-eigenvalue problem based on the assembled global matrices. The flow tubes of three bent-tube Coriolis flowmeters were modelled and the finite element analysis results were in good agreement with experimental data. The results suggested that the developed finite element method can provide reasonably accurate simulation for Coriolis flowmeters. Belhadj et al. [47] further developed the finite element method using ANSYS to simulate pulsating flows on a range of geometrically different Coriolis flow tubes (straight and bent). From the validated results, they concluded that there were some signal components from beating between the pulsation frequency and the drive frequency.

Wang and Baker [48] investigated, using a finite element (FE) model of flow tubes, the effect of manufacturing variation on the performance of the Coriolis flowmeter. Wang et al. [49] reported on an advanced and extended numerical model for single straight-tube Coriolis flowmeters to include more practical components. The predictions of the model agreed well with the data from the manufactured meters. The optimisation of these models should also introduce factors relating to the precision of the manufacturing options, as these are likely to have an influence on final instrument performance. Combined with new materials this should lead to production methods which provide an increasingly high quality product with wide applicability.

Bobovnik et al. [50] firstly used a CFD (computational fluid dynamics) code to simulate a straight beam-mode Coriolis flow tube. The deflection of the tube was prescribed in each time step and the moment created by fluid forces was used to evaluate the sensitivity. The authors recognized that the deflection of the flow tube was not calculated in this approach. Distortion of the velocity profile was identified and it was suggested that tube vibration has a stronger influence on the velocity profile for lower Reynolds numbers. For fully developed flows under low Reynolds numbers, the flow sensitivity was shown to be less than at higher Reynolds numbers. This was followed by further work [51] using a CFD 
analysis to study the velocity profile effect on shell-mode flowmeters. Significant reduction of sensitivity at low Reynolds numbers was reported.

Wang et al. [52] described a simulation which enabled Coriolis designs to be tested in a virtual mode. It allowed dynamic response, signal processing and new designs to be checked and developed. The FEM (finite element method) code also allows pseudo data to be generated for specific points on the Coriolis flow tubes. The model has the potential for simulating the effect of both corrosion and deposition within the flow tubes. Cheesewright and Shaw [53] discussed the accuracy of such methods and suggested an approach to achieve high quality results.

Samer and Fan [54] claimed that the dynamic stiffness matrix method is capable of modelling a Coriolis mass flowmeter with a general plane-shaped flow tube. The dynamic stiffness matrix method was believed to have better accuracy and a lower number of elements than the finite element method. They suggested that damping and end conditions would be considered in future work. They also suggested that their method can be used to optimize the flow sensor design (e.g. positions of drivers and motion sensors).

Thomsen and Dahl [55] commented that detailed simulation with numerical models (for example finite element models) may provide a lot of data, but it gives little useful insight into basic dependencies between parameters. This comment is probably similar to Wang and Hussain [25] who also suggested that readily computed numerical solutions may lose much of the intuitive insight into an engineering problem so that a linear damping model to study the individual contribution of nearby modes was used instead of a direct damping model. By using a perturbation approach, Thomsen and Dahl [55] derived analytical expressions that relate phase shift not only to mass flow but also to other possible factors. This is different from an early paper [24] which also used a perturbation method to study Coriolis flowmeters, but only studied the phase shift due to mass flow. Thomsen and Dahl [55] used their analytical approach and concluded with an interesting comment that nonsymmetrical damping can induce phase shifts in the overall phase shift signal in the same manner as the flow.

Enz [56] used a perturbation analysis with two mode expansion and provided simple analytical expressions for phase shift under two conditions: asymmetrically applied driving force and asymmetrically located motion sensors. With the analytical predictions, the author concluded that both types of asymmetry can contribute to the overall phase shift signal. However, the asymmetrical driving combined with tube damping contributes to zero 
related phase shift while the asymmetrical sensor position contributes differently to sensitivity related phase shift. Comparison with numerical solutions showed good agreement with analytical solutions on representative examples. Enz et al. [57] in a later paper reported an experimental examination of some of these effects.

Haneveld et al. [58] described a lumped parameter model for their development of a micromachined Coriolis flow sensor. The lumped parameter model uses two differential equations to describe the angular rotation of drive and Coriolis modes, where each mode is characterized by its own parameters. With this governing equation, mass flow rate is related to the angular motion ratio between the Coriolis mode (detection mode as used by the authors in their paper) and drive mode (actuation mode as used by the authors in their paper).

These theoretical models share the same principle of coupling the fluid and structure analyses directly where the coupling does not involve an iterative two-way procedure. These models have proved to be very useful in understanding the fundamental principles of Coriolis flow measurement and in developing better instruments. However, there is still a gap between the direct coupling models and fluid-structure interaction involved in the practical operation of Coriolis flowmeters. A typical example is that the tube motion affects the fluid velocity field, but the affected fluid velocity field in turn also disturbs the tube motion. This two-way interaction would need an iterative coupling model which has appeared recently in publications.

Having recognized the limitation of their earlier work [50,51], Bobovnik et al. [59] developed an iterative coupling method to simulate a straight flow tube. In this method, they used a finite volume code, Comet, for the fluid domain and a finite element code, Abaqus, for the structural domain in a staggered coupling procedure. Natural frequencies and phase shifts were estimated from velocity values due to free vibration at the sensing positions using a signal processing method (e.g. discrete Fourier transform). Comparisons with previous models (beam theory coupled with one dimensional flow model and Flügge shell theory coupled with a potential flow model) were provided. The authors commented that the modelling assumptions used in such an iterative coupling method were "certainly believed to be the best among the compared models".

Mole et al. [60] described an improved iterative coupling method which was first described by Bobovnik et al. [59]. This improved method can simulate forced vibration, which was believed to be a better resemblance to the true operation of Coriolis flowmeters. 
Unlike their previous work where free vibration response was used, measured characteristics were obtained from a steady-state response instead. This method was applied to study the Reynolds number effect on a straight flow tube and results were compared with the existing weight vector theory [21]. Reasonable agreement was demonstrated.

Kumar et al. [61] conducted numerical simulations using iterative coupling for fluidstructure interaction. The aim was to study the effect of Reynolds numbers, in particular low Reynolds numbers for high viscosity fluids. An example simulation for a twin bent-tube Coriolis flowmeter was shown and the simulation result was compared to experimental results. The comparison showed general agreement from $\operatorname{Re} 1,000$ to 100,000 .

\subsubsection{Signal processing and control techniques}

Kolahi et al. [62] recognized the difficulty of measuring gas flow using conventional Coriolis flowmeters because Coriolis forces generated by gas flow under normal pressure are "about three orders of magnitude smaller than those resulting from liquid flow". In order to improve the sensitivity, matching of the drive and Coriolis modes (bending and torsion eigenfrequencies as used in their paper) was proposed. The authors used a negative feedback of the displacement continuously to tune the eigenfrequencies. To control the eigenfrequencies, measurement of phase shift between bending moment and bending displacement was conducted. This phase shift was controlled in a phase-locked loop (PLL) to a reference value of $-90^{\circ}$. In the experimental results, zero drift with static pressure was evident up to 2.5 bar. The authors suggested zero offset compensation could be done with "modulation of velocity coupling" and further investigations were necessary.

Clarke [63] discussed non-linear control of the oscillation amplitude of a Coriolis flowmeter. He proposed positive feedback of the output velocity to cancel the internal damping and described the method of determining the gain, and the insertion of an inverse non-linearity in the loop to create a linear system. The approach appeared to be valid and effective. Henry et al. [64] discussed a self-validating (SEVA) digital Coriolis mass flowmeter. They listed a number of improvements which they had developed over the analogue transmitter performance: "high-precision control of flow tube operation, including at very low amplitudes; the maintenance of flow tube operation even in highly damped conditions; high-precision, high-speed measurement; compensation for dynamic changes in amplitude; compensation for two-phase flow; batching to/from empty." They claimed that these advantages had been achieved while reducing the probable manufacturing costs. 
Morita and Yoshimura [65] also described digital processing of the sensor signals and selfcalibration. They claimed that the result was "100 times as accurate" as using a discrete Fourier transform.

Henry et al. [66] highlighted the differences and advantages of an "all-digital" converter design in comparison to existing designs where the signal path had been partly or wholly analogue. One of the most important differences in the all-digital design is the capability of digitally generating a synthesized drive signal in addition to digitally processing motion signals.

Kolahi et al. [67] described a lumped parameter model for a single straight-tube flowmeter. The dynamics of the flow tube were expressed by two transfer functions which are coupled with each other. In order to determine the characteristics of the flow sensor during normal operation, they proposed to use supplementary online information. Two possible approaches were described: one using additional sensors and the other using a supplementary excitation by a model-based control system.

Harrold [68] confirmed the improved performance from digital signal processing. Henry [69] reviewed the improvements due to the digital approach and in particular the possibility of using the flowmeter for batching, due to its robustness to conditions when batching to and from empty. Clark et al. [70] described a very high response rate Coriolis flowmeter based on a commercial twin straight-tube meter with the developed digital transmitter. Their results suggested an order of magnitude, at least, increase in response speed. Henry [71] discussed a digital transmitter with a time constant equal to one cycle of the drive frequency and with a flow tube design to produce high first mode resonant frequencies, improved meter drive and signal processing procedures with high dynamic response potentially available.

Kutin et al. [72] realized a PLL (phase-locked loop) controller using the LabVIEW programming environment. The characteristics of such a resonance control system were presented together with some theoretical simulations.

Tombs et al. [73] and Henry et al. [74] discussed their all-digital Coriolis mass flow transmitter which had been developed and was able to maintain flow tube operation throughout all conditions of two-phase flow. Key to this technology was the transmitter's ability to respond quickly to flow condition changes and this was also reflected in the meter's ability to track changes in flow rates accurately with a fast dynamic response. They presented results from two- and three-phase flow experiments at Cranfield University 
using a prototype transmitter, which suggest how such a meter may be used as part of a multi-phase metering facility.

Henry et al. [74] reviewed the requirements for a Coriolis flowmeter to obtain mass and density measurements in a two-phase flow. A key aspect of this is the drive system for the vibrating tube. The need for a meter capable of this is of increasing importance. Henry et al. [75] identified in a case study the key requirements for Coriolis flowmeters operating in two phase flows as: ensuring that the flow tube vibration is sustained, correctly responding to the mass flow and density measurements. In this case study, they concluded that, while there is no generally applicable flowmeter for such flows, there may be the possibility of developing an approach for a specific meter, application and fluids. Currently any operation is limited to specified fluid mixture, and flow tube using empirical models, but the authors consider that with these constraints the meter may be usable.

Röck and Koschmieder [76] described a control method where phase and amplitude control can be done simultaneously. An extended Kalman Filter was used instead of a conventional low pass filter. It was believed that using the Kalman Filter would allow much faster estimation of the phasors. The presented control method reduced the cycle time by a factor of two compared with their previous work and would help under multiphase conditions. Koshmieder and Röck [77] also described the transfer functions of two input forces and two output velocity signals. A model-based control system was presented which enables the control of a Coriolis flow sensor under different compensation modes.

\subsubsection{Effects of process conditions}

Levien and Dudiak [78] gave a brief review of effects on Coriolis flowmeters due to temperature, pressure, vibration and flow profile, and appeared to be demonstrating their view that some Coriolis flowmeter designs could perform well.

Keita [79] presented his theoretical analysis for both pressure and compressibility effects in comparison with experimental results for straight-tube Coriolis flowmeters measuring gases. The theoretical analysis showed an overall trend of a positive change of sensitivity due to pressure changes though there might be certain numerical round-off errors. By comparing the pressure and compressibility effects, he suggested the main contribution to sensitivity change was due to pressure on the flowmeters he studied.

Cascetta [80] discussed the effect of fluid pressure on Coriolis mass flowmeter performance. He noted that since the meter operation is related to the elastic deformation of the tube, it would be necessary to compensate for changes of temperature and 
pressure. The stiffness of the system decreased with increase in temperature, while the rigidity of the tube increased with fluid pressure. The meter appeared to underestimate flow rate with increased pressure.

Bose [81] described some experimental results of two different commercially available bent-tube flowmeters. The flow calibration factor increased (thus sensitivity decreased) with increased pressure. They also reported that there was a correlation between the ratio of two fundamental frequencies and pressure. If pressure can be determined with such a known correlation, flow sensitivity change could be corrected.

Paton [82] described test results to evaluate the effects of process conditions on two Coriolis flowmeters ${ }^{\dagger \dagger}$ in a mass intercomparison project. Tests carried out by two laboratories between $5^{\circ} \mathrm{C}$ and $70{ }^{\circ} \mathrm{C}$ showed a slight fall in $\mathrm{K}$-factor of less than $0.03 \%$ in one meter and $0.2 \%$ in the other meter. Tests carried out by one laboratory using a kerosene prover loop from $0.14 \times 10^{6} \mathrm{~Pa}$ to $1.54 \times 10^{6} \mathrm{~Pa}$ showed a reduction in K-factor of $0.13 \%$ in one meter and $0.2 \%$ in the other meter. Tests carried out by four laboratories with water and other fluids ranging in viscosity up to $70 \mathrm{~mm}^{2} / \mathrm{s}$ (or cSt) and density from $780 \mathrm{~kg} / \mathrm{m}^{3}$ to $1020 \mathrm{~kg} / \mathrm{m}^{3}$ showed no density effect and little viscosity effect at high flow rates. However, below $4 \mathrm{~kg} / \mathrm{s}$ for the $70 \mathrm{~mm}^{2} / \mathrm{s}$ fluid, a reduction in K-factor of $0.15 \%$ in one meter and $0.6 \%$ for the other meter was noted.

Smith [83] demonstrated the effect of pressure on the frequencies of both bending and shell vibration modes using test results and finite element analysis. Under his test conditions, the responses of four tested gases for a shell mode implementation showed positive pressure sensitivity (the slope of frequency vs. pressure is positive). However, for a bending mode implementation all gases showed negative pressure sensitivity.

Wang and Hussain [25] used a theoretical method to explore the pressure effects on Coriolis flowmeters. They commented that most of the recent designs have a relatively small sensitivity to pressure changes compared with older designs with reference to Cascetta's earlier experimental work [84]. In the main the results presented from various manufacturers suggests that change of reading was of order $0.01 \% / \mathrm{bar}$ in most cases. They also reported an interesting finding that the general trend of pressure effect is

\footnotetext{
${ }^{t \dagger}$ The information on flowmeter sizes was not available. The maximum tested flow rate was $8 \mathrm{~kg} / \mathrm{s}$ while the minimum was $0.5 \mathrm{~kg} / \mathrm{s}$.
} 
different between bent-tube (generally negative pressure sensitivity) and straight-tube flowmeters (generally positive pressure sensitivity).

Having obtained the higher order solution of the modelled straight flow tube, Kutin and Bajsic [44] suggested that the non-ideal nature of the measuring characteristics, in particular for high flow velocities, could be corrected. This correction relied upon a simple iterative procedure where density measurement and flow measurement are dependent on each other. This fluid velocity effect can also be seen in earlier work by Keita [79].

Kenbar [85] reported experimental results from using bent-tube Coriolis flowmeters under cryogenic conditions (liquid nitrogen typically at temperatures around $-193{ }^{\circ} \mathrm{C}$ ). Wang and Hussain [86] analysed the effects of cryogenic temperatures on Coriolis mass flowmeters and addressed the problems of varying Young's modulus and thermal expansion. Unlike elevated temperatures where material properties change nearly linearly with temperature, within cryogenic temperatures strong non-linearity may exist. Thus this non-linearity of material properties has to be considered and relevant correction needs to be applied. The calibration using a NIST cryogenic facility was claimed to be within "the claimed accuracy for reference conditions" if appropriate correction is used.

Hemp [40] calculated the sensitivity of a straight-tube meter with free ends and found a velocity profile (Reynolds number) dependence. The question as to whether the Coriolis flowmeter is affected by velocity profile has been re-examined by Bobovnik et al. [51] for the shell-mode meter. They appeared to suggest that the signal may be reduced by as much as 8 percent when the Reynolds number drops to 3,000 and the flow profile (axisymmetric) is consequently changed. Kutin et al. [87] using a weight function approach indicated that while the velocity profile effect for a beam-mode Coriolis flowmeter was less significant, the effect for the shell-mode is more significant. However, they also made the point that for the new generation of Coriolis flowmeters aiming at uncertainties less than 0.1 percent, the effect of profile may need to be considered even for the beam-mode meters. In a further paper [88] they considered further parameters on which velocity profile effects might depend. Kutin et al. [21] discussed the effects of velocity profile further, and suggested that this might be responsible for small changes in flow measurement sensitivity, although there appears to be a need for more evidence of its significance before this can be accepted with certainty.

Eckert [89] stated that for certain geometry of flow tubes (when diameter to length ratio is greater) the influence of the velocity field may cause an additional error from $0.1 \%$ to 
1\%. A method of using Reynolds number for correcting this error was described. Kumar et al. [61] reported that at low Reynolds numbers a Coriolis flowmeter may deviate under the influence of fluid dynamic forces. They claimed that the effect could be explained by a periodic shear mechanism which interacted with the oscillatory Coriolis force. The effect appeared to be due to the change in axial flow profile at low Reynolds number with a change in the flow profiles from turbulent to laminar transition. The reported investigations suggested that a periodic or time-dependent mechanism due to the interaction of oscillating inertial and oscillating shear force gave rise to the shift in the meter reading. Their results suggested that at $\mathrm{Re}=2000$ a shift of order $-0.7 \%$ (i.e. under-reading) was found both in theory and experiment. The authors observed that the meter under consideration could calculate Reynolds number and so provide compensation.

Miller and Belshaw [90] reported flow tests on commercial Coriolis flowmeters with elevated fluid viscosities. Four different fluids (kerosene, gas oil, lubricant oil and Primol mineral oil) were used covering viscosities from 2 to $300 \mathrm{~mm}^{2} / \mathrm{s}$. Two calibration references were available in the facility: one was the so-called primary reference using weigh tanks achieving $0.03 \%$ uncertainty $(\mathrm{k}=2)$ while the other one was the secondary reference using a reference meter with an established calibration history achieving $0.08 \%$ uncertainty $(\mathrm{k}=2)$. Test results on two Coriolis flowmeters from two different manufacturers showed flow errors close to manufacturers' specifications for relatively low viscosity fluids (1 to $10 \mathrm{~mm}^{2} / \mathrm{s}$ ). However, for high viscosity fluids (10 to $300 \mathrm{~mm}^{2} / \mathrm{s}$ ) under-reading was observed for mass flow errors. Particularly for lower flow rates, the flow errors were "consistent with a zero adjustment error" although zero calibration was done automatically. Density measurement was reported to be unaffected by increasing fluid viscosity. With additional results on ultrasonic flowmeters and a clamp-on sonar meter, the authors concluded that it will "almost certainly be important to also address its viscosity turndown" for a flowmeter similarly to the common practice of using a flow rate turndown.

Hays and Patten [91] noted that the density of a process fluid may not affect the flow rate measurement for most flowmeters at most densities. However, in certain flowmeter designs (e.g. low flow rate Coriolis flowmeters as they noted), density effects on mass flow measurement were observed, and at that time it was "unknown what causes these errors". Test data on a flowmeter with $3.3 \mathrm{~mm}$ diameter tube was shown. Fluids with different densities by mixing water with isopropanol covering a range from $789 \mathrm{~kg} / \mathrm{m}^{3}$ to $996 \mathrm{~kg} / \mathrm{m}^{3}$ were used. It was reported that with densities that are not proximate to water density the 
instrument gives errors greater than $0.1 \%$. A method was proposed to correct these errors by using a density compensation factor.

Fyrippi et al. [92] reported flow measurement results using three different types of flowmeters, electromagnetic, single-beam ultrasonic and Coriolis flowmeters, on nonNewtonian flows. According to their study, they suggested that flowmeters which are sensitive to velocity profiles would have problems with accuracy when measuring nonNewtonian liquids. They found that the Coriolis flowmeter appeared not to be affected by non-Newtonian rheology, while the electromagnetic flowmeter exhibited about $1 \%$ error and the ultrasonic flowmeter showed up to $18 \%$ error, presumably due to flow profile change between the Newtonian and non-Newtonian, which they measured using a laser Doppler anemometry (LDA).

\subsubsection{Compressibility and sound speed}

In order to study the compressibility effect, Keita [79] proposed a "fluid effective mass model" and suggested mass flow sensitivity is reduced due to the fact that the effective mass of a compressible fluid oscillating within the tube is less than its true mass. Thus, the compressibility effect could make a Coriolis flowmeter under-read (i.e. the flowmeter gives a negative error). Anklin et al. [93] further investigated the effect of speed of sound on Coriolis mass flowmeters, and obtained a correction for high speed gas flows which may be of the order of a percent.

Cage and Dragnea [94] described the principle and a method to compensate for the compressibility effect. They commented that when Coriolis flowmeters are used to measure compressible fluids (including most gases and vapours) the frequency response of these compressible fluids greatly affects the accuracy. The errors may be significant and can be highly dependent upon the design of the flowmeter. A compressible fluid in itself can be regarded as a structural system of certain mass, stiffness and damping (i.e. an MSD system), where mass is related to fluid density and stiffness is related to fluid's bulk modulus and damping is related to fluid viscosity. As with any MSD system, the fluid inside the flow tube has natural resonances coupled with the flow tube. Therefore, a compressible fluid reacts according to its frequency response characteristics unlike an incompressible fluid. Transverse fluid modes of vibration were shown with finite element analysis. Furthermore, in order to compensate the compressibility effect, they suggested a method of employing two working frequencies (either beam-mode or shell-mode) so that the frequency response of the fluid can be determined. 
Hemp and Kutin [95] noted that previous theoretical work on compressibility effect either had disagreement with other findings or did not provide full theoretical derivation. They presented a much fuller discussion and gave the full derivation of simple formulae for density and mass flow measurement errors due to compressibility. Starting from fundamental physics, they commented that if the fluid in a Coriolis flow tube is compressible, its own stiffness due to compressibility may introduce a possible resonance at a frequency normally much higher than the drive frequency. This higher frequency has an order of magnitude of $c / d$, where $c$ is the sound speed in the fluid and $d$ tube internal diameter. Thus, if the drive frequency is getting higher or the compressibility-related frequency is getting lower (e.g. due to smaller sound speed or larger tube diameter), the influence of compressibility is getting more noticeable. This is because the fluid will move at a higher speed than the tube unlike the ideal condition where the fluid and tube move at the same speed. A lumped-parameter model was firstly presented using a two-degree (2D) of freedom mass-spring system. They found that the effective mass is greater than the static fluid mass, which is different from an earlier work [79]. A continuum mechanics model was then provided using a $2 \mathrm{D}$ equation of motion. The derived mass flow error is positive and its fractional value is equal to $\left(\frac{\omega_{d}}{c / d}\right)^{2} / 8$, which is in general agreement with the experimental observation from Anklin et al. [93].

Gysling [96] described a lumped parameter aero-elastic model for Coriolis flowmeters operating on aerated fluids. The theoretical approach was set out and the author showed that the mass flow shown by the meter was in good agreement for low operating frequencies, but diverged from the correct value with higher frequencies of operation. The same was found for the density measurements. The author suggested that the augmentation of the output from the meter by a sound speed measurement could be used to improve the outputs on mass flow and density.

For gases there are various questions raised in the literature about the accuracy of a gas Coriolis flowmeter. Effects due to compressibility and other features of the gas could mean that, for the highest accuracy, the meter becomes sensitive to type of gas. Having recognized the effect of compressibility, Haeberli and Eckert [97] and Weinstein et al. [98] suggested various methods to determine speed of sound and make correction accordingly. 


\subsubsection{Gas flow measurement}

Stewart [99] undertook experimental tests to ascertain the use of Coriolis flowmeters in gas flow and the validity of a water calibration for such an application. The meters were within $\pm 0.1 \%$ for the water calibration, and for one of the meters, mostly within about $\pm 0.5 \%$ for air calibrations. However, some showed unexpected behaviour.

Grimley [100] presented test results on Coriolis flowmeters with natural gas. This is a very useful paper which gives confidence in its data. Five Coriolis flowmeters from three different manufacturers were tested. Two manufacturers provided beam-mode twin benttube flowmeters, while the other manufacturer provided a shell-mode flowmeter. Natural gas flows from 12 to 70 bar (or 180 to 1000 psi) were tested with a critical nozzle as the reference. A "baseline meter installation" condition was used to establish a reference for comparison with the results obtained under various installation conditions (e.g. upstream elbows, tees, and reducers). The author commented that the application of water calibration to gas flow measurement showed promise. If the increased line pressure effect was appropriately corrected, water calibration seemed to be applicable to natural gas measurement within the uncertainty level of the critical nozzle reference. The author also reported that zero of tested beam-mode flowmeters was insensitive to static line pressure. Installation effect tests also showed beam-mode flowmeters were generally less sensitive to upstream flow condition changes.

Cascetta et al. [101] noted that the use of natural gas in automotive applications implied a "metrological dichotomy" because natural gas is measured by volume when it is supplied to a pumping and storage station, but compressed natural gas (CNG) is measured by mass when a vehicle is filled with gas. Measurements by means of volumetric methods are due to historical and standardisation reasons and natural gas is conventionally sold or purchased in units expressed as standard cubic meters. In order to investigate the metrological behaviour of two different types of installed flowmeters (a turbine meter at the distribution station and a Coriolis flowmeter at the dispenser), field tests were conducted in a CNG filling station. It was found that some 10\% deviation between these two types of flowmeters was observed due to accuracy difference, plant design and process conditions. Based on their test results, the use of mass flowmeters in legal measurements was recommended. 


\subsubsection{Multiphase and multicomponent flows}

Skea and Hall [102] presented their gas-in-oil test results up to $15 \%$ gas void fraction on two Coriolis flowmeters (one is a straight-tube flowmeter, while the other is a bent-tube flow meter). The main phase is oil with density $865 \mathrm{~kg} / \mathrm{m}^{3}$ and viscosity $10 \mathrm{~mm}^{2} / \mathrm{s}$ (by controlling its temperature at about $50{ }^{\circ} \mathrm{C}$ ), while the gas phase is nitrogen. On one flowmeter, with void fractions at $6 \%$ and $9 \%$, the volume flow errors were from $-15 \%$ to $+5 \%$. This Coriolis flowmeter, however, showed difficulties in handling higher gas void fractions probably due to the change of the flow pattern. On the other flowmeter, with up to $15 \%$ void fraction, the volume flow errors were all negative down to $-10 \%$. Skea and Hall [103] also presented results with water/oil mixture flows on three Coriolis flowmeters. Water-in-oil or oil-in-water flows with fractions by volume up to $15 \%$ were tested. One of the smaller size straight-tube Coriolis flowmeters performed well within $0.3 \%$ error bands by volume flow measurement, while the other two showed problems at low flow rates. The authors commented that the separation of oil and water at low flow rates might have been responsible. They also noted that the Coriolis flowmeters might have been more accurate if mass flow had been measured.

Henry et al. [104] $]^{\ddagger \ddagger}$ suggested that the use of a digital flow converter can provide improved performance for aerated liquid flow measurement. They noted that experiments have shown "substantially improved performance in the presence of aeration relative to traditional analog flowmeters" and "it also is significant to note that the digital flowmeter operates at high levels of aeration". The enhanced capability of handling aeration is mostly due to the advantages of digitally synthesizing the drive signal as highlighted by Henry et al. [66]. Several correction means were proposed to correct measurement errors under aeration conditions. The bubble effect correction is based on the assumption that the effect on the observed mass flow will be similar to the effect on the observed density (i.e. gas void reduces density, thus also reduces mass flow). The damping factor correction is based on the damping effect of aeration on the tube motion. The sensor balance

\footnotetext{
护 For some patents, the publication of an early priority application may result in a number of other publications (of their applications) in different countries and regions and even in the same country or region. These related publications are often called a patent family. For this reference [104] as an example, there are at least 6 US publications from 2001 to 2010 when searching in European Patent Office's online patent database (Espacenet). Although the earliest application was in US, the earliest publication was actually in this EP patent [104] in 1999. Considering the fact that a patent family may have a very complicated family tree, and also considering that the focus of this paper is on technical aspects, exactly identifying the earliest publication for each patent is beyond the scope of this paper. Therefore, the citation to a particular patent publication in this paper should be regarded as the reference to a typical patent publication in its patent family rather than to the earliest publication.
} 
correction is based on density differences between different ends of the tube, which can reflect in the motion sensor signal difference between inlet and outlet. Other possible corrections were also mentioned. Considering that it is not just a single contributing factor, a technique of using the neural network to predict a mass flow error and to generate a correction factor was claimed by Henry and de la Fuente [105].

Liu et al. [106] explained in detail the neural network technique. They noted that a multilayer perceptron (MLP) network can give a compact solution suitable for real-time implementation. The trained neural network can take internal sensor parameters (such as observed density, damping, sensor balance, phase sensor signal, apparent flow rate and temperature) and provide correction. On-line correction in a digital converter showed mass flow errors corrected from as high as $20 \%$ to be within $2 \%$ and most are considerably better. Interestingly, they noted that the bubble theory [107] only predicts a negative error. However, the uncorrected experimental errors under high flow rates and low density drops could provide positive errors by as much as $1 \%$.

Al-Khamis et al. [108] compared the performance of a U-tube meter, a modified U-tube meter and a twin straight-tube meter in a multiphase test unit designed to measure oil and gas rates, and water cut of oil wells. The performance of the U-tube meters deteriorated significantly when gas flowed with the crude, but the straight tube meter was less sensitive. The orientation and tube geometry affect accuracy (cf [109] and [110]). Hemp and Yeung [111] undertook tests with air/oil and air/water to check a modification of an earlier theory [107], allowing for the effect of viscosity. Reizner [112] also identified the limitation for Coriolis flowmeters when dealing with entrained gas. Adejuyigba et al. [113] discussed the possibility that digital control of Coriolis flowmeters might allow their use in limited multiphase conditions.

Anderson et al. [114] tested two Coriolis mass flowmeters in NEL's multiphase flow facility. In oil/water mixtures of about $50 \%$ water cut in vertically installed meters, they appeared to find differences in the density measurements which they considered significant, but less in the mass flow readings. The horizontal installations with various orientations resulted in significant under-reading in density in unconditioned flow when the oil and water phases became significantly separated at low velocities. In certain orientations water hold-up occurred as the flow rate approached zero. Mixing immediately upstream of the meter in all cases appeared to remove errors. They suggested that the 
static pressure should be high, presumably to ensure that cavitation does not occur at high velocities.

With the modified bubble theory to consider the liquid viscosity for aerated liquid flow measurement, Hemp and Yeung [115] described a technique to correct measurement errors by applying a viscosity correction factor. This factor is a complex function depending on the bubble diameter, liquid viscosity and oscillation frequency. In one extreme case where the liquid viscosity is zero, this viscosity correction factor is a real value equal to 3 , which predicts negative mass flow errors $-2 \alpha /(1-\alpha)$ where $\alpha$ is the gas void ratio. In another extreme case where the liquid viscosity is infinite, this factor becomes 1, which predicts no mass flow error. Any realistic liquid viscosity thus should fit somewhere in between. Consequently, if the gas void ratio and liquid viscosity can be determined for aerated liquid flows, measurement errors can be reduced by applying the correction technique based on the modified bubble theory.

Mattar [116] suggested that digital technology may allow the flowmeter to handle twophase flows. In certain circumstances, where the two phases are known, of constant specification and with predictable properties, the meter may be suitable, e.g. water cut may be measurable, but as a generally applicable instrument there are strong reservations (cf [74] and [75]). For two or more components in the flow there are problems in the use of these meters, although claims have been made for their use in certain slurry and other flows. The problem arises due to the possibility that the components can move relative to each other. Relative motion may possibly be neglected if the phases are of similar density.

It is worth noting that Hemp and Kutin [95] commented that the bubble theory (the effect due to the relative motion between bubbles and the liquid) presented earlier by [111] can be combined with the compressibility effect to estimate both density and mass flow errors. However, in addition, asymmetric damping was also suggested to be another factor to which attention should be given. Since gas/liquid mixture can cause damping on the flow tube, small asymmetrically distributed damping may cause large mass flow errors.

Drahm and Rieder [117] also noted that the "bubble theory" (see Hemp and Yeung [111] \& [115]) predicts negative density and mass flow errors and it cannot explain positive errors observed in some experiments. Thus the compensation method based on this theory could over-correct for aerated liquid flow measurement. In order to account for the positive errors found in practice, they suggested that there must be further effects that 
influence the measurement besides the bubble theory. The moving resonator effect was believed to be one of the important effects. This moving resonator model is similar to the discussion by [95] on the compressibility effect. In the proposed moving resonator model (MRM), a fluid resonator exists in addition to the structural tube resonator. If gas is entrained in liquid, the sound velocity in the gas/liquid mixture decreases dramatically even with a small amount of gas. The sound velocity in a mixture is often lower than in either of its individual phases. The reduced sound velocity decreases the mixture stiffness, thus also greatly reduces the resonance frequency of the mixture in the tube.

As discussed by Drahm and Rieder [117], using the proposed moving resonator model, if two unknowns, the gas void ratio $\alpha$ and the resonance frequency of the fluid resonator $f_{0}$, can be determined, both the bubble and moving resonator effects can be included in a compensation scheme. Two compensation schemes were suggested. One is called the two-mode (or multimode) compensation scheme, where an additional resonance frequency is detected in addition to the drive frequency. The other is called the driving mode damping compensation scheme, where the damping value at the drive mode is determined. Both compensation schemes could be used to estimate $\alpha$ and $f_{0}$. Thus, correction for aerated liquid flow measurement can be achieved. Experimental results with air/water mixture flows were reported and the correction showed improvement on mass flow and density measurement errors from uncorrected $-9 \%$ to within $+/-1 \%$ at gas void ratio about $6 \%$.

As a further development to their previous work on two-phase flows [75], Henry et al. [118] described another empirical method by combining a Coriolis flowmeter with a water cut meter to achieve three-phase flow measurement. Good measurement performance was demonstrated and they commented that other technology combinations may also be advantageous in particular for detecting or measuring slip between phases.

\subsubsection{External operating conditions}

Paton [82] also described test results to evaluate the effects of operating conditions on two Coriolis flowmeters in the mass intercomparison project. Test carried out by one laboratory by stretching at $2.6 \mathrm{kN}$ and compressing at $7.8 \mathrm{kN}$ showed no significant change in the calibration results at high flow rates. However, on one of the flowmeters, a small zero shift was seen. Vibration tests across the frequency range from 50 to $2000 \mathrm{~Hz}$ showed 3 or 4 identified frequencies where the results became unstable. 
Cheesewright and Clark [119] had shown that if an external frequency is at the drive frequency, then there would be an error in flow measurement, but Cheesewright et al. [120] also indicated that external vibrations not at the drive frequency could be isolated with correct signal analysis. Clark and Cheesewright [121] tested meters from five manufacturers for the effect of external vibration. They found that all the meters showed errors when the vibration was at the drive frequency, but the extent of error for Coriolis and other frequencies depended on the design of the manufacturer's software.

Cheesewright et al. [122] also investigated the effects of external factors on the accuracy of Coriolis flowmeter calibration. These are tabulated under: flow pulsations at Coriolis frequency, flow pulsations at drive frequency, mechanical vibrations at Coriolis frequency, mechanical vibrations at drive frequency, disturbances at other frequencies which indirectly excite the Coriolis frequency, swirl in the inlet flow, asymmetric inlet profile, increased turbulence in the inlet flow, two-phase flow (air/water), cavitation, and installation stresses. They concluded that almost all Coriolis flowmeters were affected by vibrations at the Coriolis frequency. Other frequencies could also affect the calibration. Inlet flow conditions had little or no effect, but air/water flows introduced errors. The authors concluded that while it was not generally possible to provide corrections for the error conditions, it would be possible to monitor the meter signals and generate warnings of most conditions apart from frequencies near the drive frequency.

Ma and Eidenschink [123] found that complete body rotation of the Coriolis flowmeter could lead to signal errors and should be avoided.

Storm et al. [124] suggested that the readings of the meter may be subject to parameter variation, such as liquid properties, operating conditions and installation. In the latter they gave an example of change in meter supports of the outlet pipe for a single tube meter. The problem of support and of vibratory transfer between the meter and the neighbouring pipe has been recognised by the manufacturers, who have introduced means to minimise the effects.

Cheesewright et al. [125] concluded that flow pulsations caused two separate effects that may excite additional tube motions: internal vibrations of the tube by direct interaction; beating with the driven motion of the meter to produce motions at frequencies that are the sum and difference of the pulsation frequency and the drive frequency.

Henry et al. [66] suggested that Coriolis flowmeters had poor dynamic performance in the past, but many other advantages. In another paper, Henry et al. [126], clearly stated 
that the newly developed digital converter was capable of providing much improved dynamic performance. A time constant as low as 16 ms was demonstrated, which was regarded as particularly important for applications involving short batches.

Further study of the response by Cheesewright et al. [127] using analytical, FE and experimental data indicated that the time constant could not be less than one period of the drive frequency, and that longer response times may be due to additional damping in the signal processing to reduce the effect of unwanted oscillations. Clark and Cheesewright [128] suggested that Coriolis flowmeters had the potential for outstanding dynamic performance. Clark and Cheesewright [129] investigated the response to step changes in flow rate of representative commercial flowmeters both of the flow sensor and of the complete flowmeter. They indicated that the dynamic response tends to be limited by the converter technology rather than the flow sensor, and, therefore, should be capable of considerable improvement.

Clark et al. [70] assembled a new flowmeter with an adapted commercially available straight tube and using the Oxford digital transmitter. The meter was tested in the laboratory and in the field and had delays of an order of $4 \mathrm{~ms}$ between change of flow and change of output signal.

\subsubsection{Zero stability effects}

The effects of non-proportional damping on zero shifts have been explored by [130]. A finite element model of the meter was perturbed to simulate the damping. It was shown that even very small off-diagonal terms in the damping matrix can cause a significant zero shift because of the modal superposition of undesirable modes.

Schott et al. [131] commented that Coriolis flow sensors and signal processing methods had been unable to distinguish between signals due to mass flow rate related effects and boundary condition related effects. Boundary condition effects are related to zero offset. If zero offset is not properly calibrated, measurement accuracy can be affected particularly at low flow rate. They suggested that improvement on this can be achieved by specifically sensing on a plurality of locations along the measuring section on the flow tube and through the understanding of the flow tube vibration motion that results from Coriolis forces as opposed to the vibration motion that results from changing boundary conditions. This achievement can improve the performance, in particular, for unbalanced designs which use a single measuring tube loop. In a preferred embodiment, five motion sensors were mounted along the measuring section of a single straight tube. With the additional motion 
sensors other than the traditionally used two motion sensors, two types of information can be separated: mass flow induced motion data and boundary condition related motion data, which provides information for a "true zero". Thus with a true zero determined, measurement accuracy is improved even if boundary conditions change.

In the sensor-based approach [67], acceleration sensors were used additionally to detect the flow sensor's mounting condition. The relationship between zero offset and operating conditions was determined experimentally. They reported an improvement on the accuracy of zero offset by "a factor of 3". In the model-based approach, a second eigen-mode was excited to provide supplementary information. The authors presented equations to determine both sensitivity and zero offset. They mentioned that this modelbased approach improved the accuracy of zero offset by "a factor of 8", but they concluded that it was costly and had to be tested in practice.

Schott et al. [132] further recognized that although the effects of various factors (such as temperature, pressure, stress etc.) on flow measurement sensitivity have been dealt with extensively, zero has been a more "elusive parameter" for manufacturers to control. This is because zero shifts can be caused by a number of subtle and interrelated electromechanical conditions which may be difficult to predict. The effects on sensitivity can be characterized, measured and compensated. However, a similar approach for zero shift would be difficult due to its unpredictable causes.

Wang et al. [133] examined the zero drift effect in a Coriolis flowmeter in a temperature changing environment. It was believed that zero shift due to temperature was related, in their flowmeter being tested, to the flow sensor rather than the electronic converter. Possible reasons to cause zero shift were analysed from their test results.

Koschmieder and Röck [77] also noted that the sensitivity and zero of the Coriolis flowmeter may change due to temperature gradients along the measuring pipe or due to mounting conditions. In order to achieve high accuracy, these changes need to be detected and corrected. They used a model based control system to estimate the zero point during normal operation for single-phase flow. They reported that by "exploiting the characteristics of both of the compensation methods, the zero point can be corrected either in a cyclic procedure or by separating the measurements in frequency domain".

Wang and Hussain [134] noted that zero calibration is a critical operation to ensure high accuracy measurement, but the traditional procedure of simply taking the mean time delay to obtain zero may be subjected to an uncertainty due to other effects during zero 
calibration. A procedure to consider the standard error of the mean and other statistical properties is proposed to improve the zero calibration operation. Experimental results under different zero conditions demonstrated the benefit of such an improved method.

\subsubsection{Calibration and verification}

Following JCGM 200:2012 (VIM) [135], for a Coriolis flowmeter, the calibration can be defined as the operation under a specified condition to determine measurement from raw signals using calibration factors and to establish the relationship between measurement and a reference standard. A full calibration for mass flow measurement is normally done in a gravimetric calibration facility. Verification is different from a full calibration and may be broadly defined as the operation to partially confirm the uncertainty associated the calibration [136].

Paton [82] described calibration results on two Coriolis flowmeters connected in series in the mass intercomparison project covering 10 laboratories in 9 countries. Different calibration methods, such as gravimetric/volumetric and standing/flying start and stop, were used and no difference could be seen due to calibration methods. He noted that, at the high end of the flow range (the highest flow rate was $8 \mathrm{~kg} / \mathrm{s}$ ), Coriolis flowmeters can be stable over time and location to $+/-0.15 \%$. However, at the lower end of the flow range (the lowest flow rate was $0.5 \mathrm{~kg} / \mathrm{s}$ ), the stability and agreement between laboratories rose to $+/-0.5 \%$ at best and $+/-1 \%$ at worst. Zero stability was believed to be the major issue. Thus, he concluded that the principle of using a Coriolis flowmeter as a transfer standard "has been proved when the high flow end of the flow range is used".

Wang and Hussain [137] explored the limits of accuracy in the measurement of batch flows, common in industry, but also used for calibration of flowmeters. A theoretical understanding for a short batch is also provided by numerical simulations of both deterministic and probabilistic parameters. The simulation results agreed with the batch tests and explained the experimental findings.

Standiford and Lee [138] reported intercomparison test results using two Coriolis flowmeters (a 1-inch flowmeter and a 3-inch flowmeter) tested in several different facilities including external laboratories. Flow rates were chosen to minimize possible zero errors (e.g. flow rates were typically greater than $25 \%$ of the nominal flow rate according to the figures). They concluded that the comparison results supported the claimed uncertainties of $0.014 \%(k=2)$ for the high accuracy liquid flow calibration facilities and $0.030 \%(k=2)$ for the production calibration facilities. 
Verification of a Coriolis flowmeter can be done in the field using a prover or through other verification methods. Small Volume Provers (SVP) have become increasingly used in industry for checking the calibration of custody transfer meters.

In a manual to guide the proving for Coriolis flowmeters [139], it was noted that there are three reasons for proving: custody transfer, quality audit and environmental audit. Proving differs from calibration because it is performed in the field under operating conditions which could be significantly different from the calibration condition. Available equipment for proving Coriolis flowmeters includes: gravimetric tanks, volumetric tanks, conventional pipe provers, small volume provers, volumetric master meters and Coriolis mass master meters. The procedures required to prove a Coriolis flowmeter with a conventional pipe prover or a small volume prover are detailed in the manual. It was noted that proving Coriolis flowmeters requires special consideration. An important aspect of Coriolis flowmeters is that "their measurement is time based, not pulse based". In contrast, traditional turbine or positive displacement meters produce pulses as the primary outputs. Coriolis flowmeter pulses are generated or synthesized by the microprocessor in the flow converter with certain filtering characteristics (e.g. output damping value). Thus, the proving result can be affected by meter response time and prover pre-run duration.

Tombs et al. [140] discussed the use of a small volume prover in conjunction with the newly developed flow converter (or transmitter as used in their paper) and highlighted some of the constraints on proving results, for instance, associated with pulse rate and shortness of proving period. They noted that a prover pass using SVP can be as short as $1.5 \mathrm{~s}$ which raises the questions regarding dynamic response including output damping and noise conditions. Using their latest signal processing technique implemented in a flow converter connected to a commercial flowmeter, test results showed repeatability less than $0.05 \%$ over the range and an average repeatability of $0.017 \%$ without applying any damping on the pulse output signal. A novel filtering technique to correct raw phase difference was also described based on the relative rate of change of amplitude. This technique employs the relationship between the effects of the Coriolis mode on the amplitude and phase calculation for each motion sensor signal.

Shimada et al. [141] conducted tests on several different types of flowmeter using the primary flow standard and a small volume prover in the same light oil flow rig at the National Metrology Institute of Japan. By comparing the difference between SVP proving and the primary standard calibration, they were able to investigate the effect of the sudden 
flow rate change during short-duration proving runs (the shortest proving run was $1 \mathrm{~s}$ at high flow rate). The test results indicated that turbine and positive displacement flowmeters are mostly not affected by proving runs when comparing SVP K-factors with primary standard K-factors. However, "flowmeters that employ computer-based converters" showed large uncertainties owing to the SVP. Coriolis flowmeters tested showed differences in K-factors from 0.1 to $0.5 \%$. On one of these the output damping effect was investigated by varying the time constant. The output damping did not affect the calibration using the primary standard. However, the output damping had a significant effect on SVP proving runs. With a smaller damping time constant and longer proving duration (e.g. at lower flow rates), K-factors from SVP runs are close to K-factors from primary standard calibration. Shimada et al. [142] during development of a calibration rig found that the settings in the flowmeters could also have a significant effect on their accuracy if there was any flow pulsation present.

Patten and Stack [143] claimed that, if the fluid density is known, the calculated density from a Coriolis flowmeter in comparison with the known value may be used to verify a Coriolis flowmeter. Baker et al. [136] further noted that this is effectively a check on the resonant frequency since their numerical simulation indicated a correlation between frequency and flow sensitivity due to manufacturing variations.

Baker et al. [144] noted that the density of the flowing material might not be known. Thus the check on one resonant frequency is not sufficient to verify a Coriolis flowmeter. They proposed a verification method by checking a plurality of frequencies (including both resonant and off-resonant frequencies) and parameters associated with the frequencies can also be evaluated. By comparing the recorded oscillation response with previously recorded responses against predetermined threshold values, verification of the original calibration may be achieved.

Cunningham [145] recognized the high correlation between tube stiffness and the flow calibration factor. A verification method based on stiffness measurement was proposed. In this method, off-resonance frequencies are excited in addition to the drive frequency and the embedded electronics estimates a frequency response function based on a single degree of freedom mass-stiffness-damping system. The relative deviation of the measured stiffness from the factory baseline stiffness is recorded and can be presented to users. Finite element analysis to simulate corrosion and erosion was conducted. Experimental 
results on a flowmeter with corroded flow tubes were shown and indicated the capability of stiffness measurement to track the change of the flow calibration factor.

Rensing and Cunningham [146] described the details of developing an embedded verification method using the flowmeter electronics. The development started with a rapid prototyping real-time system for performing modal analysis, and then the algorithm based on a single degree of freedom dynamic system was implemented in the embedded flowmeter electronics. During the real-time verification, four additional frequencies spaced apart from the drive frequency are excited simultaneously and responses are measured to provide a stiffness-based diagnostic. A few practical issues were noted such as: filtering with tightly designed notch filters, considering the excitation power limitation, and avoiding an impulsive shock. They concluded that the developed verification method was robust and could provide users with a diagnostic which ensured the Coriolis flowmeter was operating at its original factory accuracy.

\subsubsection{Size considerations}

While indicating that the Coriolis flowmeter approaches the ideal flowmeter, Reizner [112] identified one of its limitations, its size for larger pipe sizes. Flowmeters, above a nominal three or four inches (about $100 \mathrm{~mm}$ ), can become exceedingly large, heavy and expensive. Wang and Hussain [26] also discussed size ranges and noted that Coriolis flowmeters had been mainly developed and used in line sizes less than DN 100 (or 4-inch) because of the size problem. Another paper also reported their latest research and development using the straight-tube Coriolis technology [147] to extend flow measurement capacity to a high flow range. Design of the Coriolis flow sensor using a straight-tube configuration was presented, followed by a description of a special calibration procedure used in the manufacturer's gravimetric water flow rig. An extensive test programme on a typical DN 250 straight-tube flowmeter covered five different fluids and five different test references over four different locations, and results were within the well accepted custody transfer limit and confirmed the performance of straight-tube meters for high flow ranges. They appeared to indicate that average values for each test point fell within the $\pm 0.2 \%$ band.

Enoksson et al. [148] developed a micromachined flow sensor following their earlier work on a density sensor with a similar structure [149]. The flow tube structure is etched from a silicon wafer and two halves were bonded together to form the internal flow path. The single flow path consists of two rectangular-shaped measuring loops with an overall 
dimension about $9 \times 18 \times 1 \mathrm{~mm}$. The tube wall thickness is about $0.1 \mathrm{~mm}$ (thus the internal diameter is about $0.8 \mathrm{~mm}$ ). The flow tube was electrostatically excited using an external electrode at a distance approximately $30 \mu \mathrm{m}$ away from the tube surface. Using an antiphase drive mode, the drive frequency is about $6 \mathrm{kHz}$ for air [149] or $4.5 \mathrm{kHz}$ for water. Motion was also detected externally by optically focusing a laser beam on to the measuring loop. Flow tests were conducted with two different fluids, water and methanol, at different density and viscosity to verify the flow sensor was a true mass flow device. According to the test results up to $1.8 \mathrm{~kg} / \mathrm{h}$ with a mass flow reference (weighing and elapsed time), the authors suggested that the least-square fit of flow measurement sensitivities between these two fluids were approximately the same and this confirmed the true mass flow sensing capability of the developed sensor. They commented that their work demonstrated the possibility of fabricating a Coriolis mass flow sensor using a silicon micromachining technique and this technique could open up new possibilities of producing small size Coriolis mass flow sensors at relatively low cost. The authors also commented that further development was necessary to integrate the excitation and motion sensing functionality on to the flow sensor.

Mehendale [150] described the design of a Coriolis flowmeter for low flow range, and concluded that the developed flow sensor enabled the use of conventional manufacturing techniques in contrast to micromachining. The smallest flow sensor as described was capable of measuring low flow at a nominal flow rate of $100 \mathrm{~g} / \mathrm{h}$. At that time, the smallest commercially available Coriolis flowmeter had a nominal flow rate of $150 \mathrm{~g} / \mathrm{h}$ [27].

Another group [151-156] have also been developing micromachined Coriolis flowmeters. According to their latest publication, Smith et al. [156] described a microfluidic sensor which uses a plasma etched silicon tube mounted on a glass substrate. They reported that density and concentration meters based on this sensor technology had been made commercially available. However, Coriolis flowmeters based on this technology still appear not to be commercially available ${ }^{\S \S}$. Nevertheless, Smith et al. [156] showed a Coriolis flow sensor with its enclosure in a picture (see Fig.4 of their paper). Flow test results with two fluids (water and isopropyl alcohol) up to $500 \mathrm{~g} / \mathrm{h}$ using a weighing reference were reported. The test results were within an operating error envelope with a

$\S \S$ When accessing the website (http://www.mems-issys.com) in early 2014, there were only density and concentration meters available under the product section. 
+/-0.5\% base accuracy value. Clark et al. [157] also discussed their theoretical work to evaluate such a micromachined Coriolis flow sensor using the numerical simulation method.

Haneveld et al. [58] described the design and fabrication for a micromachined Coriolis flow sensor together with some measurement results. A sensor design was described to overcome the low sensitivity problem of previous work [148] where "a relatively heavy and stiff tube" with silicon as the tube material was used. Instead, Haneveld et al. [58] used silicon nitride as the tube material and suggested that the silicon nitride surface channel technology allowed fabrication of suspended tubes with arbitrary topology. In their design, a single rectangular-shaped tube with an internal diameter $40 \mu \mathrm{m}$ and wall thickness approximately $1.2 \mu \mathrm{m}$ was used. The maximum tube length was $10 \mathrm{~mm}$ and the rectangular shape was $2.5 \mathrm{~mm}$ by $4 \mathrm{~mm}$. With this tube shape, the nominal flow rate (water flow rate at 1 bar pressure drop) is targeted not to exceed approximately $1 \mathrm{~g} / \mathrm{h}$. In order to drive the tube into a torsional vibration, a constant external magnetic field was created using two rare earth permanent magnets. When $A C$ current flows through a metal track along the tube, electromagnetic force excites the tube. A maximum amplitude in the order of $10 \mu \mathrm{m}$ was described. The drive frequency was $3 \mathrm{kHz}$ for air and $1.8 \mathrm{kHz}$ for water. On the chip, Coriolis effect was detected using a capacitive principle, where comblike structures were designed to function as a parallel plate capacitor. An external laser vibrometer was also mentioned to sense the Coriolis effect. Flow measurement was conducted with reference to flow rate calculated according to an inlet pressure sensor and the flow was generated by a syringe pump up to $1.2 \mathrm{~g} / \mathrm{h}$. Three fluids, water, ethanol and argon, were used to test the flowmeter. Sparreboom et al. [158] further described a Coriolis flowmeter incorporating such a flow sensor enclosed in a stainless steel housing with electrical and mechanical connections to the outside world.

Lötters et al. [159] described their attempt to combine a thermal flow sensor and another Coriolis flow sensor together on the same chip in order to achieve a dynamic flow range of "more than five decades". The Coriolis flow sensor was based on the same design as Haneveld et al. [58] and was connected with the micromachined thermal sensor in series. Both sensors have the same diameter, but the thermal sensor can be used to measure much lower flow rate. Tested with water flow generated by a syringe pump and using the pump rate as a reference, the combined flow sensor showed a measurable flow range from $100 \mu \mathrm{g} / \mathrm{h}$ to $18 \mathrm{~g} / \mathrm{h}$. Interestingly, at $18 \mathrm{~g} / \mathrm{h}$ the pressure drop was about $18 \mathrm{bar}$, 
which was believed not to be a problem in HPLC (high-pressure liquid chromatography) applications. Wiegerink et al. [160] also described the design of a micromachined Coriolis flow sensor used in a by-pass setup. The micro-scale sensor (with an internal diameter about $40 \mu \mathrm{m}$ ) was intended for measuring high purity grade hydrazine $\left(\mathrm{N}_{2} \mathrm{H}_{4}\right)$ in micro chemical propulsion systems. With the by-pass ratio at 1:20 or 1:80, the measurable flow range can be extended to 20 or $80 \mathrm{~g} / \mathrm{h}$.

\subsubsection{Multi-parameter}

Kalotay [161] used an additional differential pressure sensor across a Coriolis flowmeter to measure viscosity, thereby making use of the pressure drop across Coriolis flowmeters.

Using his experimental and theoretical analysis on the effect of pressure on both bending and hoop mode frequencies, Smith [83] proposed that "pressure measurements are practical using a non-intrusive sensor" in addition to flow, density and temperature which had already been implemented in commercial Coriolis flowmeters.

Drahm and Bjønnes [162] used the torsional vibration of a single straight-tube Coriolis flowmeter, which causes a consequent rotary motion of the fluid, to obtain the viscosity of the fluid. Drahm and Staudt [163] summarised developments with reference to a particular manufacturer and noted viscosity measurement as one of the important innovations. Test results with fluids of different viscosities and densities in comparison with a laboratory viscometer were shown. The viscosity measurement accuracy was $+/-5 \%$ in general from 1 to $10,000 \mathrm{mPa} \cdot \mathrm{s}$ for Newtonian fluids.

Kolahi and Storm [164] described a lumped parameter model to simulate Coriolis flow sensors. Using the transfer function for this model, two possible methods to determine the stiffness were proposed. In the first method, only a single additional excitation frequency near the first vibration mode is used. In the second, two additional excitations are used. Using the frequency response at the additional excitation, it is possible to extract the stiffness information. Since a flow tube's stiffness is related to its temperature, mechanical stresses and internal pressure, if temperature and mechanical stresses are known (e.g. by using a temperature sensor and strain gauges respectively), the calculated stiffness change is a measure of pressure. Experimental data obtained on a Coriolis flowmeter ranging up to 60 bar showed a strong correlation between calculated stiffness and applied pressure. 


\subsubsection{Other interesting topics}

In considering Coriolis flowmeters, we note that there may be overlaps with other devices using vibration to obtain mass flow. Kim and Kim [165] proposed the use of three accelerometers, and the application of wave decomposition theory to the vibration signals. The method appeared to depend essentially on the same theoretical basis as the Coriolis flowmeter using the beam theory [24]. The same governing equation as Raszillier and Durst [24] was solved using a one-dimensional wave propagation theory. Flow rate was related to the change of wave numbers between stationary and flowing fluids.

Boyle [166] described a rotary-type Coriolis flowmeter for bulk solid flow measurement. The flowmeter consisted of a rotating measuring wheel with several guiding vanes around a central deflection cone. The measuring wheel is driven at a constant angular velocity. The torque signal is used to provide a measure of mass flow rate. A speed sensor is used to detect the angular velocity. In laboratory tests, dry quartz sand flow was used and compared with a weighing reference. The recorded errors were "generally better than $0.5 \%$ " in the range of 1 to $10 \mathrm{t} / \mathrm{h}$. Fahlenbock [167] commented that a flowmeter based on the (rotary-type) Coriolis principle for bulk solid flows may pay for itself due to greater accuracy.

Perelshteyn [168] described a flowmeter where a swirling fluid enters a divergent nozzle. He commented that subjecting the fluid to a Coriolis force could produce a phase shift in the perturbation which is indicative of the mass flow rate. However, the measuring principle does not seem to be the Coriolis principle. Instead, it is very likely to be an angular momentum measuring principle [169].

\section{Industrial Coriolis flowmeter design}

\subsection{Typical industrial flow sensors}

A list of flow sensor designs from available publications is shown in Figure 12 (a) to (j).

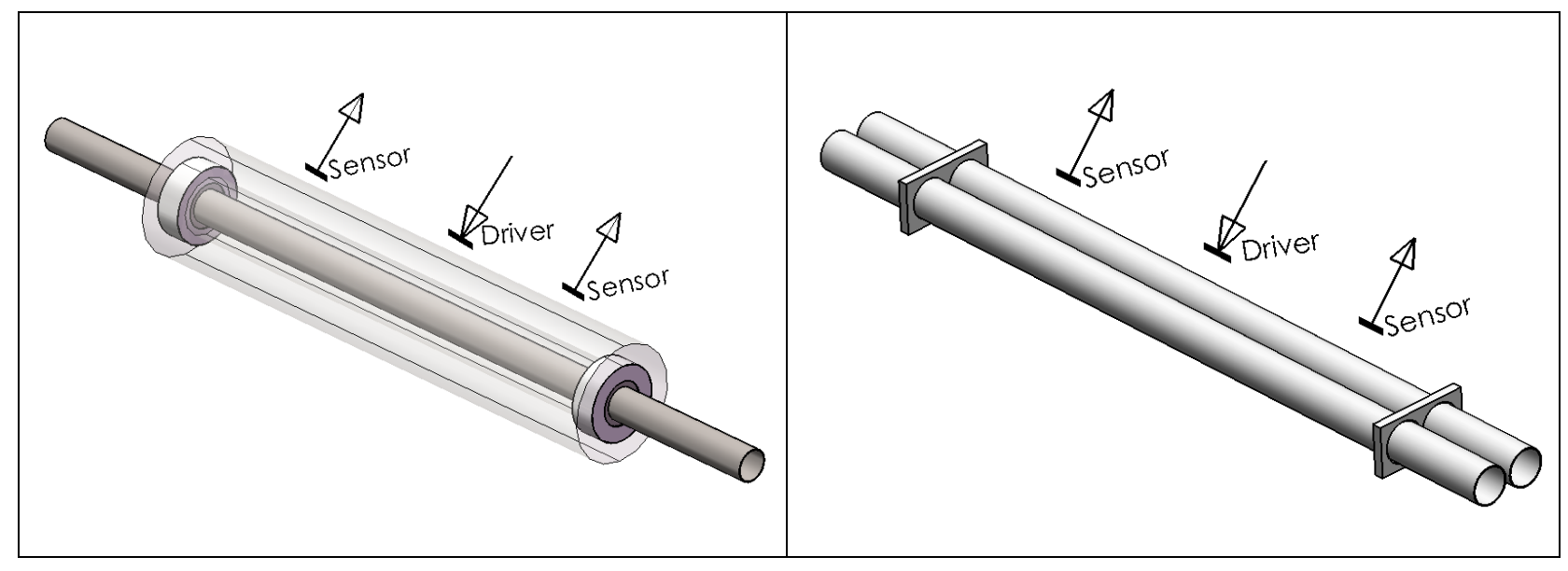




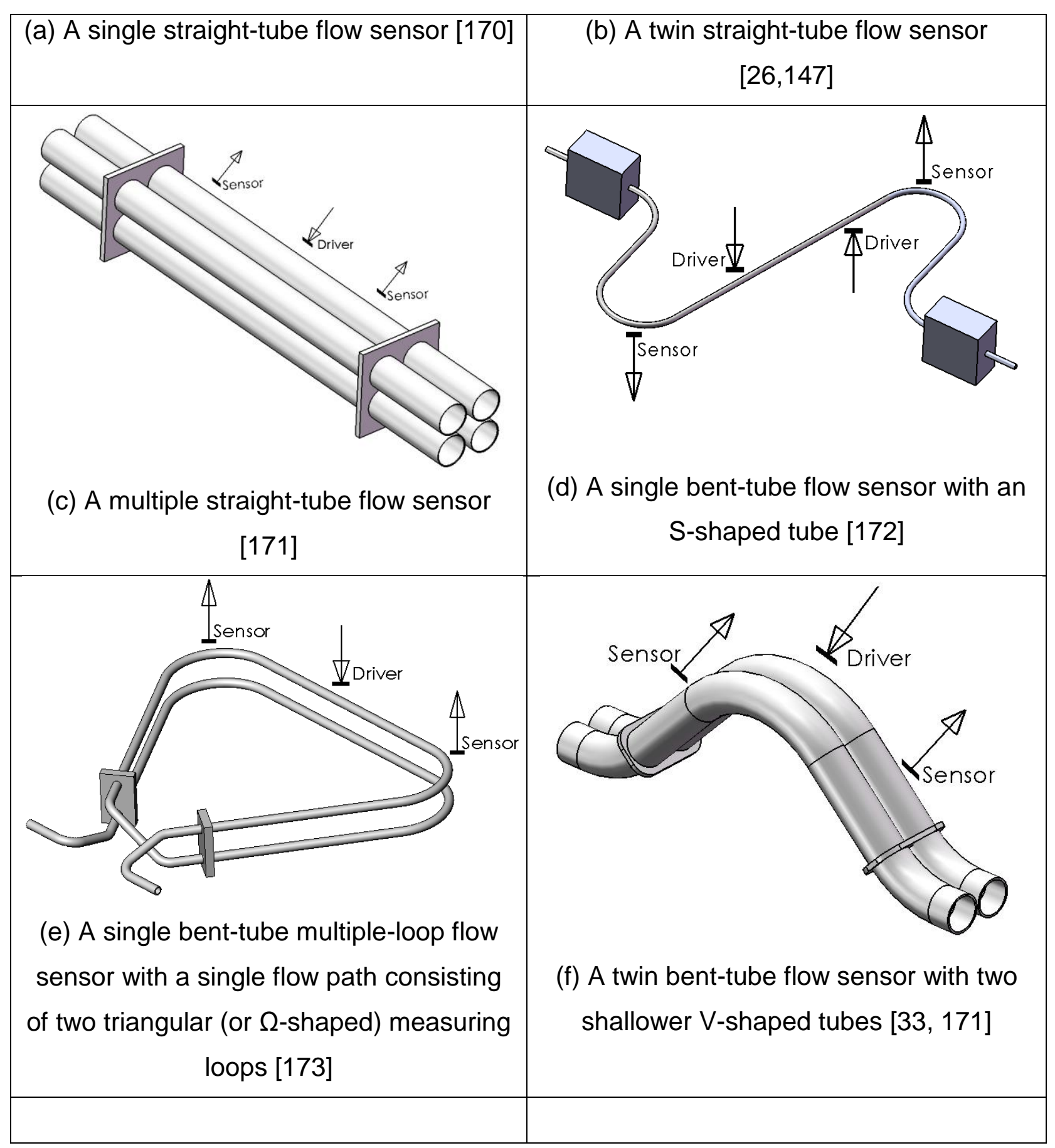




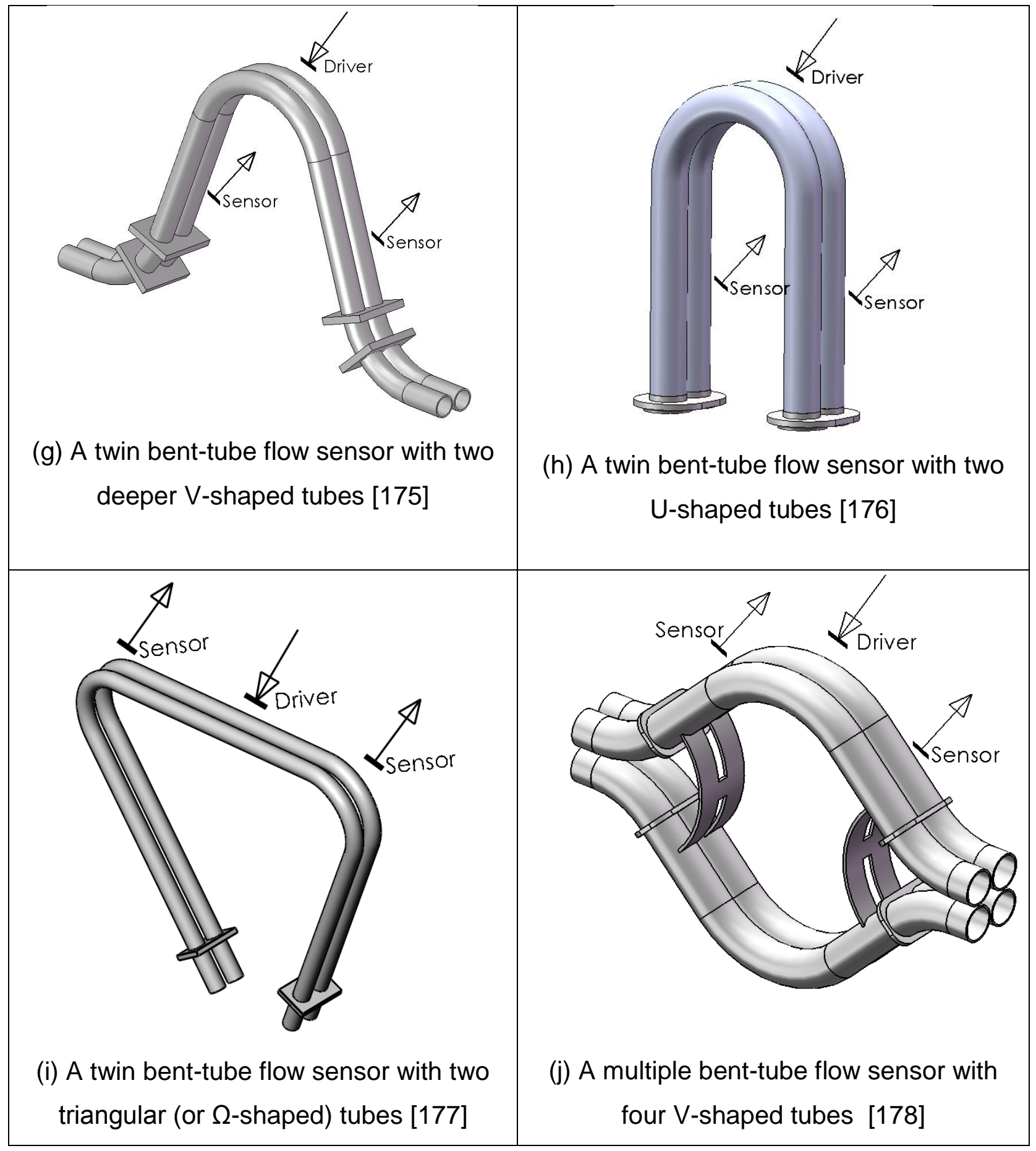

Figure 12 Typical industrial flow sensor designs

There are many other flow sensor designs which have appeared in various publications. However, it appears that the majority of current Coriolis flowmeters have simpler tube shapes, for example straight or U-shaped or modified U-shaped ( $V$ shape or $\Omega$ shape) bent tubes. 
One of the major advantages of bent-tube flow sensors is the relatively small stress under non-uniform temperature distributions (or temperature gradients). For straight-tube flow sensors, when a hotter or colder process fluid than the environmental temperature suddenly flows through the straight tube, compressive or tensile stresses are induced because the flow tube is constrained from expanding or contracting freely. Under severe thermal shock, these thermally induced stresses may exceed the material strength. For bent-tube flow sensors, the bent flow tube is relatively free to expand or contract. Thus, thermally induced stresses are relatively small. Keita and Bitto [179] and Nakao et al. [180] both showed the influence of the depth of a V-shaped bent tube upon thermally induced stresses. It could be seen that when the bend gets deeper the stress gets less.

\subsection{Flow converters}

A flow converter may be implemented using a microcontroller, a digital signal processor (DSP), a field-programmable gate array (FPGA) or other signal processing circuits [181]. Two typical examples are shown below in Figure 14. Romano [182] disclosed a converter design of digitally processing motion signals and also digitally generating synthesized drive signal as an alternative to the analogue drive circuit. Henry et al. [183] described the implementation of various digital signal processing techniques for modern Coriolis flow converters. The advantages in terms of measurement performance compared with traditional analogue converters were clearly identified.

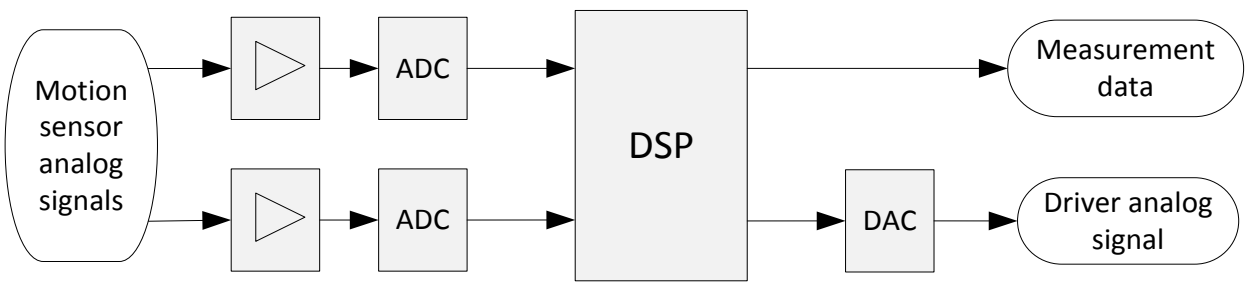

Figure 13 A typical DSP-based converter block diagram (after [184])

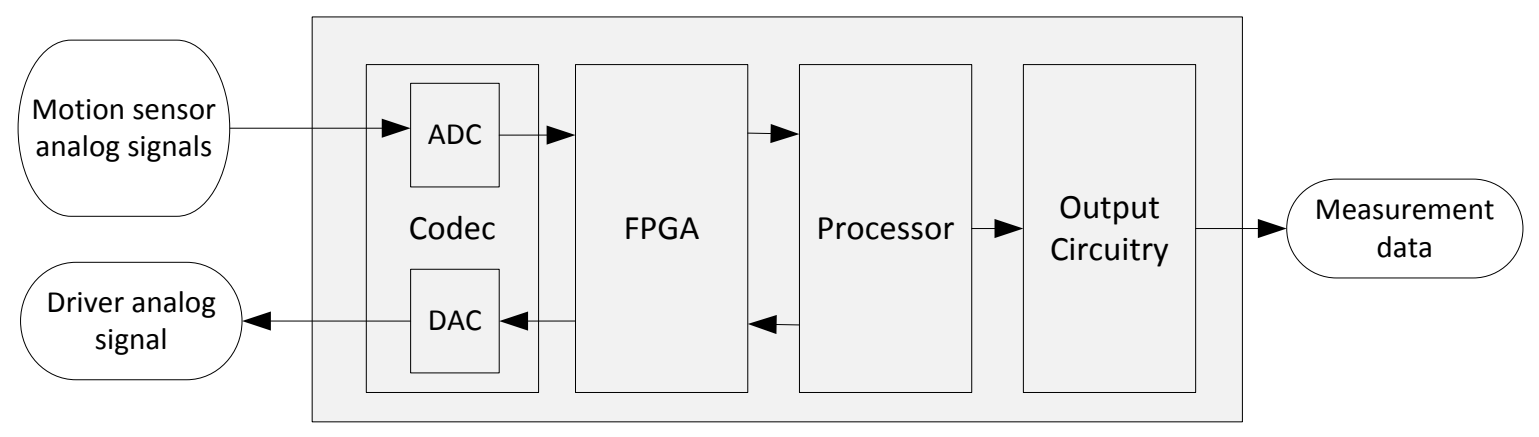

Figure 14 A typical FPGA-based converter block diagram (after [181]) 
The flow converter can be integrally mounted on the flow sensor body as a compact device, or connected to the flow sensor through a cable as a remote device. The remote configuration is particularly useful for high temperature applications or for the circumstance where the flow sensor is not easily accessible. In certain flowmeter designs, the flow converter may be physically divided into two parts, for example, a front end part and a back end part. The front end is responsible for signal processing and tube vibration control and the communication of measurement data to the back end is through a digital protocol. The front end is compactly mounted on the flow sensor body, while the back end can be either compactly mounted or remotely connected.

\subsection{Summary of typical specifications}

Technical specifications are reviewed from various publications [185-191] and summarised below in Table 1.

\section{Table 1 Specification summary}

\begin{tabular}{|c|c|}
\hline \multicolumn{2}{|c|}{ Specification summary of commercially available Coriolis flowmeters } \\
\hline Output variables & $\begin{array}{l}\text { Mass flow, volume flow, density, temperature, viscosity, } \\
\text { concentration }\end{array}$ \\
\hline Nominal line sizes & From less than DN 1 to DN 350 (1/32 to 14 inch) \\
\hline $\begin{array}{l}\text { Equivalent tube } \\
\text { diameters }\end{array}$ & From less than $1 \mathrm{~mm}$ to $205 \mathrm{~mm}$ \\
\hline Nominal flow ranges & From $100 \mathrm{~g} / \mathrm{h}$ up to just above $2,000 \mathrm{t} / \mathrm{h}$ \\
\hline $\begin{array}{l}\text { Manufacturers' base } \\
\text { accuracy specification } \\
\text { for mass flow }\end{array}$ & $\begin{array}{l}\text { Typically } 0.05 \% \text { to } 0.5 \% \text { for liquids; } 0.35 \% \text { to } 0.75 \% \text { for } \\
\text { gases }\end{array}$ \\
\hline Zero stability & From $0.002 \%$ to $0.1 \%$ of the nominal flow rate \\
\hline Repeatability & Typically half the base accuracy specification \\
\hline Wetted materials & $\begin{array}{l}\text { 300-series stainless steel, Super Duplex, Alloy C-22, } \\
\text { Titanium, Tantalum, Zirconium, PFA }\end{array}$ \\
\hline Temperature ratings & -240 up to $427^{\circ} \mathrm{C}$ \\
\hline Pressure ratings & Up to 413 bar \\
\hline \multicolumn{2}{|c|}{$\begin{array}{l}\text { Notes: } \\
\text { 1) Nominal line sizes are according to published datasheet. } \\
\text { 2) Equivalent tube diameters are calculated according to the internal tube diameter } \\
\text { and the number of flow paths. } \\
\text { 3) Nominal flow rate is water flow rate under } 1 \text { bar pressure drop, and maximum flow } \\
\text { rate for liquids and gas may be different. } \\
\text { 4) High temperature or high pressure versions are for special models found in } \\
\text { published literature. } \\
\text { 5) Uncertainty of measurement also depends on other factors such as the calibration } \\
\text { reference and measurement conditions. }\end{array}$} \\
\hline
\end{tabular}




\subsection{Other special flow sensor designs}

Clamp-on Coriolis flowmeters were described in various publications, for example [192], [193], [194], and [195]. The principle relies on using a pipe section in the existing piping system as the measuring section to sense the Coriolis force generated by the fluid and pipe interaction. In particular, Bartstra [195] described a design where the response of the measuring section is detected at multiple locations and the excitation has several different frequencies. Clearly, the difference from a conventional Coriolis flowmeter makes the determination of calibration factors a challenging task.

There are also other interesting designs. Gallagher [196] described an insertion-type sensing device which can be used to measure flow rate together with density and viscosity. van Cleve and Loving [197] described a bypass flowmeter design. Nitschke and Crowe [198] also described a device for leak detection or differential flow measurement. Stack et al. [199] showed another special configuration of flow paths in one of their multiple-tube Coriolis flowmeters.

\subsection{Shell-mode Coriolis flow sensors}

Cage [20] noted that Coriolis flowmeters with a single straight tube have some specific advantages in comparison with flowmeters with two (or more) straight or bent flow tubes. However, a single straight-tube Coriolis flowmeter using the beam-mode vibration needs special consideration for balancing. Thus, the shell-mode vibration may provide a special advantage of being a balanced resonant system since the shell mode of vibration "causes substantially no net reaction forces where the conduits are mounted". He defined the shell mode ("radial mode" used in his original text) as "a vibration mode wherein the center-line or axis of the flow conduit remains essentially unchanged while all or a part of the wall of the flow conduit translates and/or rotates away from its rest position in an oscillatory manner". Cage [20] also noted that pressure can cause stress on the flow tube and alter the stiffness - thus change the sensitivity to mass flow rate. He suggested that variation in frequencies due to pressure and density changes varies for different modes of vibration. If two shell modes are simultaneously excited, the values of two frequencies can be related to pressure and density changes.

Cage and Schott [200] further noted that the frequency response of a Coriolis flow sensor can be affected by fluid pressure, density, temperature and stress and thus it is essential to compensate or reduce the effects. For shell-mode flowmeters, they recognised that the problem of pressure sensitivity is more severe than beam-mode flowmeters 
because the fluid pressure tends to stiffen the tube wall in a shell mode more than a beam mode. They also noted that shell-mode flowmeters generally have vibration frequencies of an order of magnitude higher and flow-related time delay signals many times smaller than traditional beam-mode flowmeters. For example, a shell-mode flowmeter operates at above $3000 \mathrm{~Hz}$ with tens of nanoseconds time delay in comparison with a beam-mode flowmeter operating at about $100 \mathrm{~Hz}$ with tens of microseconds time delay. They commented that due to these limitations, although there was an existing patent for shellmode flowmeters [201] "no practical device has yet been disclosed or marketed for commercial applications". Thus improvement on the shell-mode flowmeter design was needed. By conducting finite element analyses and tests, they proposed a method to optimize the design for shell-mode Coriolis flow sensors. This method relied on the study of flow sensitivity related to four different sensing approaches (time delay, displacement, velocity, or acceleration) and various design parameters (e.g. tube length, diameter etc.). In a design example, they showed experimental results on air flow by correcting the pressure effects from nearly $15 \%$ at 28 bar (or 400 psi) to less than $1 \%$.

Hahn [202] described the, then, newly developed shell-mode Coriolis flowmeter with some initial testing results. He noted that conventional Coriolis flowmeters had some limitations for low pressure gas flow measurement. The shell-mode flowmeter might have some inherent features that could be suitable to measure gas flow. One of the features is that the drive frequency was typically greater than $2000 \mathrm{~Hz}$. Thus, greater Coriolis force can be created together with faster response time due to high drive frequency. Simulation results by CFD showed Coriolis forces along a particular axis under different flow rates. Experimental results using air flow with a sonic nozzle as reference showed $+/-0.5 \%$ accuracy.

As one of the five flowmeters tested by Grimley [100] with natural gas flows from 12 to 70 bar (or 180 to 1000 psi), the shell-mode flowmeter tested showed a change in meter factors in the range of $-1.5 \%$ to $+4 \%$. The author also reported that zero of the shell-mode flowmeter showed some nonlinear dependence on pressure unlike normal beam-mode flowmeters which were insensitive to pressure changes.

Amabili and Garziera [203] described a Coriolis mass flowmeter having a thin-walled measuring tube which oscillated in various modes with more than one circumferential wave. Exciters and sensors generate the modes and measure the distortion to obtain a 
measure of mass flow rate. Improvement on the design by further considering vibration isolation was also described by Rolph et al. [204].

\subsection{Other essential components in a Coriolis flowmeter design}

\subsubsection{Motion excitation and sensing means}

Flow tubes of the Coriolis flowmeters are normally excited by an electromagnetic means. However, other excitation means could be beneficial under some circumstances. These include electrostatic, acoustic or piezoelectric means (see for example [205]). For the electromagnetic driver, a permanent magnet and a coil as a pair is commonly used.

Apart from the excitation means described above which can be used as a motion sensing means (inductive, capacitive, acoustic or piezoelectric), other motion sensing means have also appeared in the literature as long as they can sense deformation, displacement, velocity or acceleration. Kalotay [206] described a motion sensing means using optical fibre sensors to detect displacement of the flow tube. Dakić et al. [207] also described the use of fibre-optic curvature sensors mounted on flexible tubes to sense tube motion. Barger et al. [208] described an optical means where the flow tubes move through a light path between the light source and the light detector. Brouwer et al. [209] referred to this technique as "optically transmissive". He also described another "optically reflective" means where a light beam is directed to part of the tube wall and the reflected light is detected. Cage [210] proposed the use of "a plurality of strain sensing transducers" attached to the flow tube to detect tube deflection. He suggested that the use of magnet/coil pairs might be problematic under some conditions. For example, magnets and coils could be of a significant mass compared with the tube; positioning of the magnet/coil pair to tube ends increases noise ratio; magnet/coil pairs also need significant care during assembly.

In order to excite the first fundamental bending mode, one driver is sufficient, but two or more drivers may excite the wanted mode but suppressing the unwanted ones. Typical examples of using two or more drivers are given by Cuningham and Shelley [211] or Hussain et al. [212]. Similarly two motion sensors are sufficient to detect the phase difference or time delay between the measuring sections. However, more motion sensors may have the advantage of giving more information (e.g. for correction) or providing redundancy [213]. Other examples include the use of a third sensor at the driver location [214] and [215], a third or up to fourth sensor for bend-tube designs, and four sensors for straight-tube designs [216]. 


\subsubsection{Additional sensing devices}

At least one temperature sensor (typically a platinum resistance temperature detector or RTD) is normally fitted on the Coriolis flow tube in addition to motion sensors. The detected temperature provides not only a measure for the fluid temperature but also a useful input variable to compensate the changes in the flow tube due to temperature deviation from the reference calibration condition. Other additional sensors may also be useful to compensate other effects due to different changes. Flecken and Abildgaard [217] and van Cleve et al. [218] used two or more temperature sensors to measure temperatures on both the vibrating tube and the supporting structures for straight-tube designs, which is particularly useful when temperature gradient is created across the flowmeter. van der Pol [219] proposed the use of a "length-change sensor" (e.g. strain gauges) that detects changes in the measuring tube and corrects the measurement based on the detected strain or stress for straight-tube flowmeters. Other examples of using additional sensing devices can also be found in the papers by Drahm and Rieder [220] where an additional acceleration sensor is used on the supporting structure, by Hussain [221] where an additional circumferential strain sensor is applied to detect and correct pressure changes, and by Matt [222] where an additional humidity sensor is used inside the flow sensor housing.

\subsubsection{Balancing and decoupling components}

Balancing and decoupling generally refers to the condition of vibration being balanced and confined within the internal vibratory structure so that the useful internal vibration is decoupled from the surrounding environment. Balancing and decoupling can be done through design and manufacturing. Twin tube designs are generally believed to be better balanced since two nearly identical tubes vibrate against each other so that vibration has minimum escaping to outside. However, special attention for further improvement is also needed for example as stated by [223] for twin straight-tube flowmeters and by [224] for twin bent-tube flowmeters. Single tube designs normally need special counterbalance structures. For example, Hussain and Rolph [225] described a compensation cylinder where a single straight flow tube is located inside, and Lanham and Werbach [226] described a balance system for a single bent-tube flowmeter.

\subsubsection{Flow sensor housing, process connection and other external components}

In addition to above components to form the internal measuring system, other external components are also necessary to mechanically or electrically protect the internal 
measuring system and to connect the flowmeter to a process plant. Flow sensor housing has received some attention due to their importance in improving performance apart from its normal housing function. Typical examples on flow sensor housing designs can be found in [175], [176] and [227].

\subsection{Industrial applications}

Altendorf [228] described the application in the pulp and paper industry. Dutka et al. [229] evaluated an on-line viscosity and density measurement system for black liquor from paper pulp production based on a Coriolis flowmeter. The measuring principle is according to an earlier work described by Kalotay [161]. Under laminar flow conditions, the system tracked reliably within $+/-10 \%$ of the laboratory reference viscosity for highly viscous liquors. Both steady-state and transient performance were satisfactory and the system did not experience fouling problems. Other applications also include as a possible nonintrusive pressure measurement [230] and as part of a multiphase metering unit [109]. AlMubarak et al. [110] used a Coriolis flowmeter in well rate test applications. Continuous online data capture of temperature, mass flow and mixture density from the Coriolis flowmeter enabled "well test results very successful". Dunn and Klein [231] discussed the use of Coriolis flowmeters in the production of Alkylate, and particularly the need for precise measurement of the concentration of sulphuric acid. Engelbert et al. [232] used a single straight-tube Coriolis flowmeter to measure the flow of paint and varnish, highviscosity and high pigmentation fluids. Wang and Hussain [233] described straight-tube Coriolis flowmeters specially designed for nuclear applications.

Basrawi [234] discussed the application of Coriolis flowmeters for custody transfer. Mattar [116] also suggested that the Coriolis technology has been increasingly replacing positive displacement meters for custody transfer. He also suggested the use of Coriolis flowmeters for proving, unloading railcars and tank trucks and two-phase flows. Gregory et al. [235] identified interest in accurate measurement during ship fuel bunkering. Air entrainment is a problem in bunkering operations. The paper claimed that the latest generation of Coriolis flowmeters could cope with both single- and two-phase (oil-air) flow conditions. Trials were run at NEL on a DN 200 Coriolis flowmeter. Meter accuracy was also assessed for simulated bunkering operations, when the meter was empty of oil at start and finish.

Mattar [236] particularly suggested the use of Coriolis flowmeters for ethylene oxide applications where it is at or near the boiling point and there is a danger of nitrogen break- 
out. Patten and Dunphy [237] suggested that Coriolis flowmeters are suitable for cryogenic service. De Jonge et al. [238] tested Coriolis flowmeters on liquid helium at $4.5 \mathrm{~K}$, supercritical helium around $5 \mathrm{~K}$ and superfluid helium below $2 \mathrm{~K}$. They reported that with minor changes, the meters maintained their robustness and provided accuracy better than $1 \%$.

Post et al. [239] described an interesting biomedical application of Coriolis flow sensors for organ preservation systems using machine perfusion. In the current clinical systems, ultrasonic flow sensors are used, but changes in perfusion temperature, pressure and applied preservation solution can affect measurement accuracy or require recalibration. An experimental machine perfusion system including a Coriolis flow sensor was developed. The measurement stability of this system with temperature, pressure and solution changes was confirmed through tests. However, for clinical applications, sterility guidelines and portability needs to be considered.

\section{Discussion and likely developments}

Over the past 20 years, our understanding to Coriolis flow measurement has certainly deepened and the Coriolis technology has also advanced.

For theoretical modelling of fluid-tube interaction, broadly speaking, there have been two methods to model the coupling between the fluid flow and its conveying tube: direct coupling based on beam or shell theories with assumed fluid flows; iterative coupling based on numerical models in both the structural domain (FEM) and the fluid domain (CFD). In the meantime, there have also been two general objectives for modelling: to obtain intuitive understanding through simplified models; to optimize flowmeter design through detailed modelling. In the future, iterative coupling work will be an important new direction due to the improvement of computational power and its capability to simulate more realistic details. The application of modelling work to optimize flowmeter design should also be an important aspect.

In the area of signal processing and control techniques, the application of sophisticated DSP techniques and powerful hardware has been identified through this review. In the future this trend should continue and it will bring improved performance (for example fast response and better handling of air entrainment) and added values (for example multiparameter measurement and verification or diagnostics functionalities).

The effects of operating conditions and how these conditions affect measurement are getting clearer. 
- Apart from stresses, temperature affects the tube stiffness and dimension, and its effect may be non-linear in relation to material properties [86].

- Pressure mainly affects the tube stiffness and its effect depends on the flow sensor design. Bent-tube and straight-tube flowmeters have shown different trend in the effect of pressure changes [25].

- Compressibility affects the fluid-structure interaction due to the fluid being a resonator itself. For certain flowmeter designs and operating conditions, for example high drive frequency and large tube diameter for compressible gas measurement, the effect may be more noticeable. It has been found that the effect of compressibility tends to make a Coriolis flowmeter over-read [95].

- Velocity profile generally has small effect. However, at very low Reynolds number some effects have been found theoretically and experimentally. This is due to a secondary fluid velocity field in the cross section, and the effect of low Reynolds numbers tends to make a Coriolis flowmeter under-read [82], [21] and [61].

- High fluid velocity affects the flow tube in a stiffness-like mechanism due to the centrifugal term in the governing equation [44]. For most practical applications due to the limit of pressure loss through the flowmeter, this effect is often small.

- Fluid densities deviating from the reference calibration fluid may affect Coriolis flowmeters. This is very likely due to balancing or added masses on the flow tube. However, the reported effects were generally small [91].

- Multiphase flows affect Coriolis flow measurement in a more complicated manner. Relative movement or decoupling between phases is only one of the factors. Much effort has been dedicated to aerated liquid flow measurement. The effects of aeration can include the bubble effect (depending on the liquid phase viscosity), compressibility effect and non-symmetric damping effect [105], [95], and [117].

- External stresses, vibrations and pulsating flows may affect Coriolis flowmeters [82] and [119]. But the effects are difficult to quantitatively predict since they depend on the specific condition.

- With this clearer understanding, characterisation and correction or reduction of these undesirable effects has been possible. Some effects can be accurately corrected or minimised. In the future, we anticipate that accurate measurement of multiphase flows will remain a challenge. The stability of zero will also need more careful theoretical and practical examinations. 
In the area of calibration and verification, the high accuracy of Coriolis flowmeters has been demonstrated by international inter-laboratory calibrations [82] [138]. Verification of Coriolis flowmeters using proving equipment or on-line verification and diagnostic tools has also appeared in practice. Better uncertainty calibration and improved accuracy is likely to be a continuing trend in the future. Intelligent on-line verification and diagnostic methods will also receive more attention and further development.

For industrial flowmeter design, extension of flowmeter sizes and measurement capacity has shown a clear trend towards high flow range and very low flow range, even ultra low flow range. For the high flow range, multiple tube flowmeter designs have been an important development. For the very low and ultra low flow range, single bent-tube (or with multiple loops) designs with MEMS showed their advantages. We expect this trend to continue in future developments. Optimisation of flow sensor design and implementation of on-line correction algorithms and multi-parameter measurement in flow converters should continue to improve and extend the Coriolis technology. Manufacturing cost, standardisation, and new applications are also future considerations.

There are, however, other open questions:

- Since 1986, we have seen the technology development being evolutionary. The main-stream technology for fluid flow measurement is vibratory beam-mode devices. What will be the next major development? Will the rotary-type device or shell-mode device receive further development for fluid flow measurement considering some of their advantages?

- Using the vibratory principle and additional sensors, a system mainly based on Coriolis flowmeters has been capable of providing multiple process parameters. Will a Coriolis flowmeter become a true multi-parameter instrument rather than a simple flowmeter? Or as Stevens [240] asked, are Coriolis flowmeters a universal technology?

- Will a computer model fully simulate a Coriolis flowmeter and its measurement considering its multiphysics nature including structural, fluid, electromagnetic, and possibly more physical domains?

- Can a true zero be determined or verified without stopping the flow? 


\section{Appendix}

\subsection{Coriolis flowmeter classification according to the flow sensor design}

\begin{tabular}{|c|c|c|c|c|}
\hline \multicolumn{5}{|c|}{$\begin{array}{l}\text { Coriolis flowmeter classification according to the measuring principle and configuration of flow } \\
\text { tube(s) }\end{array}$} \\
\hline $\begin{array}{l}\text { Measuring } \\
\text { principles }\end{array}$ & $\begin{array}{l}\text { Number of flow } \\
\text { paths between } \\
\text { inlet and outlet }\end{array}$ & $\begin{array}{l}\text { Shape of an } \\
\text { individual } \\
\text { measuring tube } \\
\text { section within } \\
\text { each flow path }\end{array}$ & $\begin{array}{l}\text { Number of } \\
\text { measuring loops } \\
\text { (or tube } \\
\text { sections) within } \\
\text { each flow path }\end{array}$ & Classification name \\
\hline \multirow{8}{*}{$\begin{array}{l}\text { (Vibratory- } \\
\text { type } \\
\text { beam- } \\
\text { mode) }\end{array}$} & $\begin{array}{l}\text { Single (flow- } \\
\text { path) }\end{array}$ & straight-tube & (single-loop) & $\begin{array}{l}\text { Single straight-tube } \\
\text { Coriolis flowmeter }\end{array}$ \\
\hline & $\begin{array}{l}\text { Single (flow- } \\
\text { path) }\end{array}$ & bent-tube & (single-loop) & $\begin{array}{l}\text { Single bent-tube Coriolis } \\
\text { flowmeter }\end{array}$ \\
\hline & $\begin{array}{l}\text { Single (flow- } \\
\text { path) }\end{array}$ & bent-tube & $\begin{array}{l}\text { multiple-loop } \\
(>1)\end{array}$ & $\begin{array}{l}\text { Single bent-tube } \\
\text { multiple-loop Coriolis } \\
\text { flowmeter }\end{array}$ \\
\hline & Twin (flow-path) & straight-tube & (single-loop) & $\begin{array}{l}\text { Twin straight-tube } \\
\text { Coriolis flowmeter }\end{array}$ \\
\hline & Twin (flow-path) & bent-tube & (singe-loop) & $\begin{array}{l}\text { Twin bent-tube Coriolis } \\
\text { flowmeter }\end{array}$ \\
\hline & $\begin{array}{l}\text { Multiple (>2) } \\
\text { (flow-path) }\end{array}$ & straight-tube & $\begin{array}{l}\text { (single- or } \\
\text { multiple- } \\
\text { loop, }>1)\end{array}$ & $\begin{array}{l}\text { Multiple straight-tube } \\
\text { Coriolis flowmeter }\end{array}$ \\
\hline & $\begin{array}{l}\text { Multiple (>2) } \\
\text { (flow-path) }\end{array}$ & bent-tube & $\begin{array}{l}\text { (single- or } \\
\text { multiple- } \\
\text { loop, }>1 \text { ) }\end{array}$ & $\begin{array}{l}\text { Multiple bent-tube } \\
\text { Coriolis flowmeter }\end{array}$ \\
\hline & \multicolumn{3}{|c|}{ Others (e.g. clamp-on, dissimilar flow paths etc.) } & $\begin{array}{l}\text { Special design Coriolis } \\
\text { flowmeter }\end{array}$ \\
\hline \multicolumn{4}{|c|}{ (Vibratory-type) shell-mode } & $\begin{array}{l}\text { Shell-mode Coriolis } \\
\text { flowmeter }\end{array}$ \\
\hline \multicolumn{4}{|l|}{ Rotary-type } & $\begin{array}{l}\text { Rotary-type Coriolis } \\
\text { flowmeter }\end{array}$ \\
\hline
\end{tabular}

\section{Acknowledgement}

The authors would like to thank the management of KROHNE for encouraging and supporting such a fundamental and thorough literature study on Coriolis flow measurement. We would also like to thank all reviewers for their positive and very helpful comments. We would particularly like to acknowledge our debt to our late colleague and friend, Dr Yousif Hussain, whose support and encouragement has been a major stimulus over many years. 


\section{References}

[1] Baker RC. Coriolis flowmeters: industrial practice and published information. Flow Meas Instrum 1994;5:229-46.

[2] IMS Research. End of an era for conventional flowmeters? Measurement + Control 2011;44:301.

[3] Flow Research Inc. The World Market for Coriolis Flowmeters (4th Edition) 2013.

[4] Baker RC. Flow Measurement Handbook. Cambridge University Press; 2000.

[5] Britannica. Gustave-Gaspard Coriolis (French physicist) -- Britannica Online Encyclopedia 2012.

[6] Kollsman P. Flowmeter. US2602330, 1952.

[7] USPTO. USPTO Publishes First Patent Application (Press Release \#01-13) 2001.

[8] Li YT, Lee SY. A fast-response true-mass-rate flowmeter. Trans ASME 1953;75:835-41.

[9] Pearson JM. Flowmeter. US2624198, 1953.

[10] White RB. Coriolis mass flowmeter. US2832218, 1958.

[11] Wiley WC, Goodrich GW, Adams FL. Oscillating mass flowmeter. US3080750, 1963.

[12] Sipin AJ. Mass flow metering means. US3329019, 1967.

[13] Sipin AJ. Mass flow metering means. US3355944, 1967.

[14] ACS (American Chemical Society). New flowmeters put squeeze on orifice plate. Chem Eng News 1977;55:20-1.

[15] Smith JE. Method and structure for flow measurement. US4187721, 1980.

[16] Cox BM, Gonzalez FA. Coriolis mass flow rate metering means. US4127028, 1978.

[17] Langdon RM. Mass flow measurement device. GB2071848, 1981.

[18] Smith JE, Cage DR. Parallel path Coriolis mass flow rate meter. US4491025, 1985.

[19] Mizerak DS. Apparatus and method for continuously measuring mass flow. US4622858, 1986.

[20] Cage DR. Single path radial mode Coriolis mass flow rate meter. US5373745, 1994.

[21] Kutin J, Bobovnik G, Hemp J, Bajsić I. Velocity profile effects in Coriolis mass flowmeters: Recent findings and open questions. Flow Meas Instrum 2006;17:349_ 58.

[22] Kutin J, Bajsić I. Characteristics of the shell-type Coriolis flowmeter. J Sound Vib 1999;228:227-42.

[23] Hagenmeyer $\mathrm{H}$, Wenger $\mathrm{A}$. Coriolis-type mass flow sensor with a single measuring tube. US5616868, 1997.

[24] Raszillier H, Durst F. Coriolis-effect in mass-flow metering. Arch Appl Mech 1991;61:192-214.

[25] Wang T, Hussain Y. Pressure effects on Coriolis mass flowmeters. Flow Meas Instrum 2010;21:504-10.

[26] Wang T, Hussain Y. Extending flow measurement capacity with the straight tube Coriolis technology. Proceedings of the 15th Flow Measurement Conference (FLOMEKO 2010), Taipei, Taiwan: 2010.

[27] Brooks. QUANTIM Low Flow Coriolis Data Sheet 2006.

[28] Bronkhorst. mini CORI-FLOW: Compact Coriolis Mass Flow Meters \& Controllers for Liquids and Gases 2008.

[29] API. API Manual of Petroleum Measurement Standards Chapter 5 - Metering, Section 6 - Measurement of Liquid Hydrocarbons by Coriolis Meters (API MPMS Chapter 5.6, R2008) 2002.

[30] AGA. Measurement of Natural Gas by Coriolis Meter (AGA Report No. 11) 2003. 
[31] NAMUR. Coriolis Mass Meter (CMM): NAMUR Recommendation NE 1322009.

[32] ISO. ISO 10790:1999 - Measurement of fluid flow in closed conduits -- Guidance to the selection, installation and use of Coriolis meters (mass flow, density and volume flow measurements) 1999.

[33] Tombs MS. Coriolis Special Issue. Comput Control Eng 2003;14:27.

[34] Cheesewright R, Tombs MS. Editorial. Flow Meas Instrum 2006;17:315-6.

[35] Anklin M, Drahm W, Rieder A. Coriolis mass flowmeters: Overview of the current state of the art and latest research. Flow Meas Instrum 2006;17:317-23.

[36] Païdoussis MP. Fluid-structure Interactions: Slender Structures and Axial Flow, Volume 1. London: Academic Press; 1998.

[37] Païdoussis MP. Fluid-structure Interactions: Slender Structures and Axial Flow, Volume 2. London: Elsevier Academic Press; 2004.

[38] Hemp J. The weight vector theory of Coriolis mass flowmeters. Flow Meas Instrum 1994;5:247-53.

[39] Hemp J, Hendry LA. The weight vector theory of Coriolis mass flowmeters - Part 2. Boundary source of secondary vibration. Flow Meas Instrum 1995;6:259-64.

[40] Hemp J. Calculation of the sensitivity of a straight tube Coriolis mass flowmeter with free ends. Flow Meas Instrum 2002;12:411-20.

[41] Hulbert GM, Darnell I, Brereton GJ. Numerical and experimental analysis of Coriolis mass flowmeters (AIAA-95-1384-CP). AIAA; 1995.

[42] Keita NM. Ab initio simulation of Coriolis mass flowmeter. Proceedings of the 10th International Conference on Flow Measurement (FLOMEKO 2000), Salvador, Brazil: 2000.

[43] Cunningham TJ, Hensley DP. Using IMAT and MATLAB for Coriolis flowmeter design. Proceedings of the 19th Modal Analysis Conference (IMAC-XIX), Kissimmee, USA: 2001.

[44] Kutin J, Bajsić I. Stability-boundary effect in Coriolis meters. Flow Meas Instrum 2001;12:65-73.

[45] Kutin J, Bajsić I. An analytical estimation of the Coriolis meter's characteristics based on modal superposition. Flow Meas Instrum 2002;12:345-51.

[46] Stack CP, Barnett RB, Pawlas GE. A Finite Element for the vibration analysis of a fluid-conveying Timoshenko beam (AIAA-93-1552-CP). AIAA/ASME Structures, Structural Dynamics and Materials Conference, 1993, p. 2120-9.

[47] Belhadj A, Cheesewright R, Clark C. The simulation of Coriolis meter response to pulsating flow using a general purpose FE code. J Fluid Struct 2000;14:613-34.

[48] Wang T, Baker RC. Manufacturing variation of the the measuring tube in a Coriolis flowmeter. Comput Control Eng J 2003;14:38-9.

[49] Wang T, Baker RC, Hussain Y. An advanced numerical model for single straight tube Coriolis flowmeters. J Fluid Eng-T ASME 2006;128:1346-50.

[50] Bobovnik G, Kutin J, Bajsić I. The effect of flow conditions on the sensitivity of the Coriolis flowmeter. Flow Meas Instrum 2004;15:69-76.

[51] Bobovnik G, Kutin J, Bajsić I. Estimation of velocity profile effects in the shell-type Coriolis flowmeter using CFD simulations. Flow Meas Instrum 2005;16:365-73.

[52] Wang S, Clark C, Cheesewright R. Virtual Coriolis flow meter: a tool for simulation and design. Proc Inst Mech Eng Part C-J Eng Mech Eng Sci 2006;220:817-35.

[53] Cheesewright R, Shaw S. Uncertainties associated with finite element modelling of Coriolis mass flow meters. Flow Meas Instrum 2006;17:335-47.

[54] Samer G, Fan S. Modeling of Coriolis mass flow meter of a general plane-shape pipe. Flow Meas Instrum 2010;21:40-7. 
[55] Thomsen JJ, Dahl J. Analytical predictions for vibration phase shifts along fluidconveying pipes due to Coriolis forces and imperfections. J Sound Vib 2010;329:3065-81.

[56] Enz S. Effect of asymmetric actuator and detector position on Coriolis flowmeter and measured phase shift. Flow Meas Instrum 2010;21:497-503.

[57] Enz S, Thomsen JJ, Neumeyer S. Experimental investigation of zero phase shift effects for Coriolis flowmeters due to pipe imperfections. Flow Meas Instrum $2011 ; 22: 1-9$.

[58] Haneveld J, Lammerink TSJ, de Boer MJ, Sanders RGP, Mehendale A, Lötters JC, et al. Modeling, design, fabrication and characterization of a micro Coriolis mass flow sensor. J Micromech Microeng 2010;20.

[59] Bobovnik G, Mole N, Kutin J, Stok B, Bajsić I. Coupled finite-volume/finite-element modelling of the straight-tube Coriolis flowmeter. J Fluid Struct 2005;20:785-800.

[60] Mole N, Bobovnik G, Kutin J, Stok B, Bajsić I. An improved three-dimensional coupled fluid-structure model for Coriolis flowmeters. J Fluid Struct 2008;24:559-75.

[61] Kumar V, Anklin M, Schwenter B. Fluid-structure interaction (fsi) simulations on the sensitivity of Coriolis flow meter under low Reynolds number flows. Proceedings of the 15th Flow Measurement Conference (FLOMEKO 2010), Taipei, Taiwan: 2010.

[62] Kolahi K, Gast T, Rock $\mathrm{H}$. Coriolis mass flow measurement of gas under normal conditions. Flow Meas Instrum 1994;5:275-83.

[63] Clarke DW. Non-linear control of the oscillation amplitude of a Coriolis massflowmeter. Eur J Control 1998;4:196-207.

[64] Henry MP, Clarke DW, Archer N, Bowles J, Leahy MJ, Liu RP, et al. A selfvalidating digital Coriolis mass-flow meter: an overview. Control Eng Pract 2000;8:487-506.

[65] Morita A, Yoshimura H. Method of measuring phase difference in Coriolis mass flowmeter. Proceedings of the International Conference on Advances in Instrumentation and Control, 1996.

[66] Henry MP, Clark C, Cheesewright R. Pushing Coriolis mass flowmeters to the limit. Comput Control Eng 2003;14:24-8.

[67] Kolahi K, Storm R, Röck H. Detection of zero shift in Coriolis mass flowmeters. Proceedings, XVI IMEKO World Congress, Viena, Austria: 2000.

[68] Harrold D. Coriolis flowmeters. New and improved: What's that mean? Control Engineering 2001;48.

[69] Henry MP. Coriolis meter digital transmitter technology. Comput Control Eng 2003;14:34-5.

[70] Clark C, Zamora M, Cheesewright R, Henry M. The dynamic performance of a new ultra-fast response Coriolis flow meter. Flow Meas Instrum 2006;17:391-8.

[71] Henry MP. Coriolis flow transmittter and dynamic response performance - digital transmitter. Measurement + Control 2003;36:278-81.

[72] Kutin J, Smrecnik A, Bajsić I. Phase-locking control of the Coriolis meter's resonance frequency based on virtual instrumentation. Sensors and Actuators A: Physical 2003;104:86-93.

[73] Tombs MS, Henry $M$, Yeung $H$, Lansangan RM. Coriolis mass flow meter developments: Increasing the range of applications in oil \& gas production and processing. 22nd North Sea Flow Metering Workshop, 2004.

[74] Henry M, Duta M, Tombs MS, Yeung H, Mattar W. How a Coriolis mass flow meter can operate in two-phase (gas/liquid) flow. Technical Papers of ISA 2004;454:17-30. 
[75] Henry M, Tombs MS, Duta M, Zhou FB, Mercado R, Kenyery F, et al. Two-phase flow metering of heavy oil using a Coriolis mass flow meter: A case study. Flow Meas Instrum 2006;17:399-413.

[76] Rock H, Koschmieder F. Advanced phasor control of a Coriolis mass flow meter. Proceedings, XIX IMEKO World Congress, Lisbon, Portugal: 2009.

[77] Koschmieder F, Röck H. Compensation method applied to Coriolis mass flow metering. Proceedings of the 15th International Flow Measurement Conference (FLOMEKO 2010), Taipei, Taiwan: 2010.

[78] Levien A, Dudiak A. How Coriolis meter design affects field performance. ISA TECH/EXPO Technology Update Conference Proceedings, 1995.

[79] Keita NM. Behavior of straight pipe Coriolis mass flowmeters in the metering of gas - theoretical predictions with experimental-verification. Flow Meas Instrum 1994;5:289-94.

[80] Cascetta F. Effect of fluid pressure on Coriolis mass flowmeter's performance. ISA T 1996;35:365-70.

[81] Bose T, Derby HV, Levien AK, Pankratz AW. Method and apparatus for measuring pressure in a Coriolis mass flowmeter. US5734112, 1998.

[82] Paton R. Calibration techniques for Coriolis mass flowmeters. Proceedings of the 9th International Conference on Flow Measurement (FLOMEKO '98), Lund, Sweden: 1998.

[83] Smith WC. Non-intrusive pressure/multipurpose sensor and method. US6301973, 2001.

[84] Cascetta F. Experimental investigations upon the pressure effects on two Coriolis mass flowmeters of different generation. ISA T 1999;38:149-56.

[85] Kenbar A, Hussain Y, Wang T. Calibration of a Coriolis mass flowmeter for LNG at cryogenic temperatures. The Americas Flow Measurement Workshop 2008, 2008.

[86] Wang T, Hussain Y. Coriolis mass flow measurement at cryogenic temperatures. Flow Meas Instrum 2009;20:110-5.

[87] Kutin J, Hemp J, Bobovnik G, Bajsić I. Weight vector study of velocity profile effects in straight-tube Coriolis flowmeters employing different circumferential modes. Flow Meas Instrum 2005;16:375-85.

[88] Kutin J, Bobovnik G, Bajsić I. Modelling and evaluation of velocity profile effects on Coriolis flowmeters. Proceedings of the 13th International Conference on Flow Measurement (FLOMEKO 2005), Peebles, Scotland: 2005.

[89] Eckert G, Haeberli R, Matt C, Wenger A. Coriolis mass/flow density meter. US6513393, 2003.

[90] Miller G, Belshaw B. An investigation into the performance of Coriolis and ultrasonic meters at liquid viscosities up to 300 cSt. 26th International North Sea Flow Measurement Workshop, St Andrews, Scotland: 2008.

[91] Hays PJ, Patten AT. Apparatus and method for compensating mass flow rate of a material when the density of the material causes an unacceptable error in flow rate. US6556931, 2003.

[92] Fyrippi I, Owen I, Escudier MP. Flowmetering of non-Newtonian liquids. Flow Meas Instrum 2004;15:131-8.

[93] Anklin M, Eckert G, Sorokin S, Wenger A. Effect of finite medium speed of sound on Coriolis mass flowmeters. Proceedings of the 10th International Conference on Flow Measurement (FLOMEKO 2000), Salvador, Brazil: 2000.

[94] Cage DR, Dragnea GS. System and method for fluid compressibility compensation in a Coriolis mass flow meter. US6502466, 2003. 
[95] Hemp J, Kutin J. Theory of errors in Coriolis flowmeter readings due to compressibility of the fluid being metered. Flow Meas Instrum 2006;17:359-69.

[96] Gysling DL. An aeroelastic model of Coriolis mass and density meters operating on aerated mixtures. Flow Meas Instrum 2007;18:69-77.

[97] Haeberli R, Eckert G. Coriolis-type flow meter and method for measuring the mass flow rate of a gaseous or vaporous fluid. US6412355, 2002.

[98] Weinstein J, Bell MJ, Patten AT. Method and apparatus for measuring a fluid parameter in a vibrating meter. US2011264385, 2011.

[99] Stewart DG. Performance of Coriolis meters in gas flow. The 5th International Symposium of Fluid Flow Measurement (ISFFM), 2002.

[100] Grimley TA. Installation effects testing of Coriolis flow meters with natural gas. 5th International symposium of Fluid Flow Measurement, Arlington, VA, USA: 2002.

[101] Cascetta F, Rotondo G, Musto M. Measuring of compressed natural gas in automotive application: A comparative analysis of mass versus volumetric metering methods. Flow Meas Instrum 2008;19:338-41.

[102] Skea AF, Hall ARW. Effects of gas leaks in oil flow on single-phase flowmeters. Flow Meas Instrum 1999;10:145-50.

[103] Skea AF, Hall AWR. Effects of water in oil and oil in water on single-phase flowmeters. Flow Meas Instrum 1999;10:151-7.

[104] Henry MP, Clarke DW, Vignos JH. Coriolis flowmeter with digital control system. EP0919793, 1999.

[105] Henry MP, de la Fuente MJ. Correcting for two-phase flow in a digital flowmeter. US2001045134, 2001.

[106] Liu RP, Fuent MJ, Henry MP, Duta MD. A neural network to correct mass flow errors caused by two-phase flow in a digital Coriolis mass flowmeter. Flow Meas Instrum 2001;12:53-63.

[107] Hemp J, Sultan G. On the theory and performance of Coriolis mass flowmeters. Proceedings of the International Conference on Mass Flow Measurement Direct and Indirect, London: 1989.

[108] Al-Khamis MN, Al-Nojaim AA, Al-Marhoun MA. Performance evaluation of Coriolis mass flowmeters. J Energy Resour Technol-Trans ASME 2002;124:90-4.

[109] Al-Taweel AB, Barlow SG, Aggour MA. Development and testing of multiphase metering unit utilizing Coriolis meters. Proceedings SPE Annual Technical Conference and Exhibition, Texas: 1997.

[110] Al-Mubarak AM. A new method in calculating water cut and oil and water volumes using Coriolis meters. Proceedings SPE Annual Technical Conference and Exhibition, Texas: 1997.

[111] Hemp J, Yeung H. Coriolis meters in two phase conditions. Comput Control Eng 2003;14:36.

[112] Reizner JR. Coriolis - The almost perfect flow meter. Comput Control Eng 2003;14:28-33.

[113] Adejuyigbe B, Uvwo I, Ekpecham O, Liu J, Scott SL, Lansangan R, et al. Investigation of three-phase flow measurement capabilities of a self-validating dynamic Coriolis meter. The 4th North American Conference on Multiphase Technology, 2004, p. 161-76.

[114] Anderson O, Miller G, Harvey R, Stewart D. Two component Coriolis measurement of oil and water at low velocities. 22nd North Sea Flow Metering Workshop, 2004.

[115] Hemp J, Yeung H. Viscosity-corrected flowmeter. US2005022611, 2005.

[116] Mattar W. Advances in Coriolis technology resolve tough pipeline flow measurement challenges. Pipeline and Gas Journal 2005;232:35-6. 
[117] Drahm W, Rieder A. In-Line measuring devices and method for compensation measurement errors in in-line measuring devices. US2007186686, 2007.

[118] Henry M, Tombs MS, Zamora M, Zhou F. Coriolis mass flow metering for threephase flow: A case study. Flow Meas Instrum 2013;30:112-22.

[119] Cheesewright R, Clark C. Experimental investigation of the influence of external vibrations on Coriolis mass flow meters. ASME 2002 International Mechanical Engineering Congress and Exposition, New Orleans, Louisiana, USA: 2002, p. 1109-17.

[120] Cheesewright R, Belhadj A, Clark C. Effect of mechanical vibrations on Coriolis mass flow meters. Journal of Dynamic Systems, Measurement, and Control 2003;125:103-13.

[121] Clark C, Cheesewright R. The influence upon Coriolis mass flow meters of external vibrations at selected frequencies. Flow Meas Instrum 2003;14:33-42.

[122] Cheesewright $R$, Clark $C$, Bisset $D$. The identification of external factors which influence the calibration of Coriolis massflow meters. Flow Meas Instrum 2000;11:110.

[123] Ma YM, Eidenschink T. Motion induced signals of Coriolis flowmeters. Flow Meas Instrum 2001;12:213-7.

[124] Storm R, Kolahi K, Rock H. Model-based correction of Coriolis mass flowmeters. IEEE Trans Instrum Meas 2002;51:605-10.

[125] Cheesewright $R$, Clark C, Bissett D. Understanding the experimental response of Coriolis massflow meters to flow pulsations. Flow Meas Instrum 1999;10:207-15.

[126] Henry MP, Clark C, Duta M, Cheesewright R, Tombs MS. Response of a Coriolis mass flow meter to step changes in flow rate. Flow Meas Instrum 2003;14:109-18.

[127] Cheesewright R, Clark C, Belhadj A, Hou YY. The dynamic response of Coriolis mass flow meters. J Fluid Struct 2003;18:165-78.

[128] Clark C, Cheesewright R. Coriolis flow meters/the potential for outstanding dynamic performance. Measurement + Control 2003;36:275-7.

[129] Clark C, Cheesewright R. Experimental determination of the dynamic response of Coriolis mass flow meters. Flow Meas Instrum 2006;17:39-47.

[130] Cunningham TJ. Zero shifts due to non-proportional damping. Proceedings of the 15th International Modal Analysis Conference (IMAC), 1997.

[131] Schott MN, Cage DR, Carmichael LK, Hahn DT. Signal processing apparati and methods for attenuating shifts in zero intercept attributable to a changing boundary condition in a Coriolis mass flow meter. US5827979, 1998.

[132] Schott MN, Cage DR, Carmichael LK. System and method for employing an imaginary difference signal component to compensate for boundary condition effects on a Coriolis mass flow meter. US6227059, 2001.

[133] Wang L-J, Hu L, Fu X, Ye P. Experimental investigation on zero drift effect in Coriolis mass flowmeters. Proceedings of the 15th Flow Measurement Conference (FLOMEKO 2010), Taipei, Taiwan: 2010.

[134] Wang $X$, Hussain $Y$. Method for determining at least one characteristic for the correction of measurements of a Coriolis mass flowmeter. US2011184667, 2011.

[135] JCGM. JCGM 200:2012 International vocabulary of metrology - Basic and general concepts and associated terms (VIM). 3rd (2008 version with minor corrections). JCGM; 2012.

[136] Baker RC, Moore PI, Wang T. In situ calibration. Sensor Review 2005;25:197-201.

[137] Wang T, Hussain Y. Investigation of the batch measurement errors for singlestraight tube Coriolis mass flowmeters. Flow Meas Instrum 2006;17:383-90. 
[138] Standiford DM, Lee M. Inter-laboratory comparison results for Coriolis mass flow meter calibration facilities. Proceedings of the 15th Flow Measurement Conference (FLOMEKO 2010), Taipei, Taiwan: 2010.

[139] Micro Motion. Proving Coriolis flowmeters 1998.

[140] Tombs MS, Henry M, Zhou FB, Lansangan RM, Reese M. High precision Coriolis mass flow measurement applied to small volume proving. Flow Meas Instrum 2006;17:371-82.

[141] Shimada T, Doihara R, Terao Y, Takamoto M. Calibration performance of small volume prover for several types of hydrocarbon flowmeters. The sixth International Symposium on Fluid Flow Measurement (ISFFM), 2006.

[142] Shimada T, Mahadeva DV, Baker RC. Further Investigation into a Water Flow Rig Related to Calibration. Flow Measurement and Instrumentation 2010;21:462-75.

[143] Patten AT, Stack CP. System for validating calibration of a Coriolis flowmeter. US6092409, 2000.

[144] Baker R, Wang T, Hussain Y, Woodhouse J. Method for testing a mass flow rate meter. US7603885, 2009.

[145] Cunningham TJ. An in-situ verification technology for Coriolis flowmeters. The 7th International Symposium on Fluid Flow Measurement (ISFFM), 2009.

[146] Rensing $M$, Cunningham TJ. Coriolis flowmeter verification via embedded modal analysis. IMAC XXVIII, Jacksonville, FL, USA: 2010.

[147] Wang T, Hussain Y. Latest research and development of twin-straight tube Coriolis mass flowmeters. Sens Rev 2007;27:43-7.

[148] Enoksson P, Stemme G, Stemme E. A silicon resonant sensor structure for Coriolis mass-flow measurements. J Microelectromech S 1997;6:119-25.

[149] Enoksson P, Stemme G, Stemme E. Vibration modes of a resonant silicon tube density sensor. J Microelectromech S 1996;5:39-44.

[150] Mehendale A. Coriolis mass flow rate meters for low flows (PhD thesis). Univeristy of Twente, 2008.

[151] Zhang Y, Tadigadapa S, Najafi N, Schneider R, Najafi N. A micromachined Coriolisforce-based mass flowmeter for direct mass flow and fluid density measurement. 11th International Conference on Solid-State Sensors and Actuators, Munich, Germany: 2001.

[152] Sparks D, Smith R, Cripe J, Schneider R, Najafi N. A Portable MEMS Coriolis Mass Flow Sensor. IEEE Sensors Conference, 2003.

[153] Sparks D, Smith R, Massoud-Ansari S, Najafi N. Coriolis mass flow density and temperature sensing with a single vaccum sealed MEMS chip, 2004.

[154] Sparks D, Cruz V, Najafi N. The resonant behavior of silicon tubes under two-phase microfluidic conditions with both microbeads and gas bubbles. Sensors and Actuators A 2007;135:827-32.

[155] Sparks D, Smith R, Cruz V, Tran N, Cimbayo A, Riley D, et al. Dynamic and kinematic viscosity measurements with a resonating microtube. Sensors and Actuators A 2009;149:38-41.

[156] Smith R, Sparks D, Riley D, Najafi N. A mems-based Coriolis mass flow sensor for industrial applications. IEEE Transactions on Industrial Electronics 2009;56:106671.

[157] Clark C, Wang S, Cheesewright R. The performance characteristics of a micromachined Coriolis flow meter: An evaluation by simulation. Flow Meas Instrum 2006;17:325-33. 
[158] Sparreboom W, van de Geest J, Katerberg M, Postma F, Haneveld J, Groenesteijn $\mathrm{J}$, et al. Compact mass flow meter based on a micro Coriolis flow sensor. Micromachines 2013;4:22-33.

[159] Lötters JC, Lammerink TSJ, Groenesteijn J, Haneveld J, Wiegerink RJ. Integrated thermal and micro-Coriolis flow sensing system with a dynamic flow range of more than five decades. Micromachines 2012;3:194-203.

[160] Wiegerink RJ, Lammerink TSJ, Groenesteijn J, Dijkstra M, Lotters JC. Micro Coriolis mass flow sensor for chemical micropropulsion systems. First International conference on MicroFluidic Handling Systems (MFHS-2012), Enschede, The Netherlands: 2012.

[161] Kalotay P. Online viscosity measurement using Coriolis mass flowmeters. Flow Meas Instrum 1994;5:303-8.

[162] Drahm W, Bjonnes H. A Coriolis mass flowmeter with direct viscosity measurement. Comput Control Eng 2003;14:42-3.

[163] Drahm W, Staudt W. Coriolis mass flowmeters: state of the art review and innovations. Proceedings of the 12th International Conference on Flow Measurement (FLOMEKO 2004), Guilin, China: 2004.

[164] Kolahi K, Storm R. Method for operating a mass flow meter. US2006112774, 2006.

[165] Kim Y-K, Kim Y-H. A three accelerometer method for the measurement of flow rate in pipe. Journal of the Acoustical Society of America 1996;100:717-26.

[166] Boyle KC. Accurate measurement for gypsum. Global Gypsum 2002:28-31.

[167] Fahlenbock TD. Coriolis mass flow meter: High accuracy for high flow rates. Powder and Bulk Engineering 2005;19:29-33.

[168] Perelshteyn M. Fluid mass flow meters. US5458005, 1995.

[169] Van Cleve CB, Loving RS. Coriolis effect mass flowmeter using concentric rotors. US5728951, 1998.

[170] Hussain YA, Rolph CN, Harrison N, Cook V, Davies L. Mass flowmeter. US2004173032, 2004.

[171] Hussain Y, Rolph C, Wang T. Mass flowmeter. US2010050783, 2010.

[172] Kazakis I. Mass flow meter. US5287754, 1994.

[173] Ollila CJ, Normen DF, Lister ED. Dual loop Coriolis effect mass flowmeter. US2001029790, 2001.

[174] Rieder A, Schuetze C, Anklin-Imhof M. Vibration-type measurement transducer. US2006107758, 2006.

[175] Hussain Y, Rolph CN, Wang T. Coriolis mass flowmeter. US2011259124, 2011.

[176] Griffin CR, Moore M, Pankratz AW. Vibrating flow device and method for fabricating a vibrating flow device. US2010263456, 2010.

[177] Cage DR, Ruesch JR, Cunningham TJ. Stability Coriolis mass flow meter. USRE36376, 1999.

[178] Huber C, Bitto E, Braun M, Rieder A, Schuetza C. Measuring transducer of vibration-type, as well as an in-line measuring device having such a measuring transducer. US2011265580, 2011.

[179] Keita M, Bitto E. Coriolis-type mass flow sensor. US5796011, 1998.

[180] Nakao Y, Kobayashi S, Sukemura N, Ogawa Y, Gomi S, Uchida K. Arch-shaped tube type Coriolis meter and method for determining shape of the Coriolis meter. US2004040387, 2004.

[181] Henry MP, Zhou F. Flowmeter batching techniques. US2005274200, 2005.

[182] Romano P. Coriolis mass flow rate meter having a substantially increased noise immunity. US4934196, 1990.

[183] Henry MP, Clarke DW, Vignos JH. Digital flowmeter. US2002019710, 2002. 
[184] Matt C. Method for determining the mass flow through a Coriolis mass flowmeter. US2009211373, 2009.

[185] $\mathrm{E}+\mathrm{H}$. Proline Promass 80H, 83H Technical Information (TI074D/06/en/09.08) 2008.

[186] E+H. Proline Promass 83X Technical Information (TI00110D/06/EN/02.11) 2011.

[187] KROHNE. OPTIMASS 7000 Technical Datasheet 2009.

[188] Micro Motion. High Temperature Coriolis (Downloaded 2009) 2009.

[189] Micro Motion. Technical Overview and Specfication Summary (Product Data Sheet PS-00232, Rev.K) 2011.

[190] ControlGlobal.com. Coriolis Flowmeter: The Holy Grail in Coriolis Flowmeters 2011.

[191] Bronkhorst. mini CORI-FLOW: Compact Coriolis Mass Flow Meters \& Controllers for Liquids and Gases (Downloaded 2012) 2012.

[192] Kalotay PZ. Coriolis effect mass flowmeter. US5321991, 1994.

[193] Hussain Y, Rolph CN. Mass flow meter. US2002020227, 2002.

[194] Drahm W, Rieder A, Wenger A, Koudal O. Method and corresponding sensors for measuring mass flow rate. US6360614, 2002.

[195] Bartstra RW. Clamp-on Coriolis mass flow meter using in-situ calibration. EP1623192, 2006.

[196] Gallagher JG. Transducer for the measurement of attributes of flowable media. US5670709, 1997.

[197] Van Cleve CB, Loving RS. Bypass type Coriolis effect flowmeter. US5861561, 1999.

[198] Nitschke SJ, Crowe CJB. Method and apparatus for fluid leak detection. US2008133152, 2008.

[199] Stack CP, Patten AT, Lanham GT, Bell MJ. Multiple flow conduit flow meter. US2010175456, 2010.

[200] Cage DR, Schott MN. Coriolis mass flow rate meter having adjustable pressure and density sensitivity. US5473949, 1995.

[201] Lang M, Donoso J. Method of mass flow measurement by the Coriolis principle and mass flow meter operating by the Coriolis principle. US4949583, 1990.

[202] Hahn DT. New technology directly measures mass flow of gas. The 3rd International Symposium on Fluid Flow Measurement (ISFFM), 1995.

[203] Amabili M, Garziera R. Coriolis mass flow meter. US2003089180, 2003.

[204] Rolph CN, Harrison N, Hussain Y. Coriolis mass flowmeter. US2006123924, 2006.

[205] Barger MJ, Dille JC, Whiteley JL, Scott TW. Coriolis mass flow controller. US2003131668, 2003.

[206] Kalotay PZ. Coriolis effect meter using optical fiber sensors. US5400653, 1995.

[207] Dakić BM, Bajić JS, Stupar DZ, Slankamenac MP, Živanov MB. A novel fiber-optic mass flow sensor. Key Engineering Materials 2013;543:231-4.

[208] Barger MJ, Dille JC, Scott TW, Whiteley JL. Coriolis mass flow controller. US6748813, 2004.

[209] Brouwer DM, Mehendale A, Kristiansen L, Klein MEE, Katerberg MR. Coriolis flow sensor with optically reflective motion sensor. US2010122585, 2010.

[210] Cage DR. Coriolis mass flowmeter with improved accuracy and simplified instrumentation. US6684715, 2004.

[211] Cunningham TJ, Shelley SJ. Driver for oscillating a vibrating conduit. US6092429, 2000.

[212] Hussain Y, Cook V, Rolph CN, Wang T. Device for measuring the mass rate of flow. US2007151368, 2007.

[213] Deppe L, Lesjak R, Papenbrock A. Method and device for detecting and compensating zero point influences on Coriolis mass flowmeters. US6705172, 2004. 
[214] McAnally CB, Bell MJ, Lanham GT. Three pickoff sensor flow meter. US2009272173, 2009.

[215] Huber C. Measuring system having a measuring transducer of vibrating-type. US2010257943, 2010.

[216] Hussain $\mathrm{Y}$, Wang T. Method for determining the viscosity of a medium with a Coriolis mass flowmeter. US2012048034, 2012.

[217] Flecken P, Abildgaard N. Mass flow meter operating by the Coriolis principle. US4768384, 1988.

[218] Van Cleve CB, Stack CP, Lanham GT. Straight tube Coriolis flowmeter. US6327915, 2001.

[219] Van der Pol R. Mass flow meter. US5381697, 1995.

[220] Drahm W, Rieder A. Coriolis-type mass flow meter with at least one measuring tube. US5736653, 1998.

[221] Hussain YA. Mass flow rate measuring device and process for measuring the pressure with a mass flow rate measuring device. US2004261541, 2004.

[222] Matt C. Apparatus for monitoring a measurement transmitter of a field device. US2005035867, 2005.

[223] Hussain Y, Wang T. Coriolis mass flowmeter. US2011154914, 2011.

[224] Van Cleve CB, Bell MJ. Split balance weights for eliminating density effect on flow. US7597007, 2009.

[225] Hussain YA, Rolph CN. Mass flow meter. US5476013, 1995.

[226] Lanham GT, Werbach CA. Coriolis flow meter with an improved balance system. US2010326203, 2010.

[227] Rieder A, Schuetze C, Anklin-Imhof M. Vibration-type measurement transducer. US7216549, 2007.

[228] Altendorf $M$. Coriolis technique in the pulp and paper industry. Chemical Engineering World 1998;33:87-9.

[229] Dutka AR, Basker VR, Crisalle OD, Fricke AL, Kalotay P. Evaluation of a capillaryCoriolis instrument for on-line viscosity and density measurements of kraft black liquor. TAPPI Journal 2004;3:17-24.

[230] Smith WC, Kowalski RR. Adaptation of commercial Coriolis flowmeters for nonintrusive pressure measurement. Instrumentation in the Aerospace Industry: Proceedings of the 44th International Symposium, 1998.

[231] Dunn DG, Klein M. Alkylation unit optimization using Coriolis mass flowmeters. Texas A\&M Instruments Symposium, 2003.

[232] Engelbert C, Scheulen R, Incontri J. Successful flow measurement in varnish production. World Pumps 2007:24-5.

[233] Wang T, Hussain Y. Coriolis flowmeters for nuclear applications. Measurement + Control 2011;44:58-60.

[234] Basrawi YF. Coriolis force mass flow measurement devices. Proceedings of the 49th International Instrumentation Symposium, ISA - The Instrumentation, Systems, and Automation Society; 2003.

[235] Gregory D, West M, Paton R, Casimiro R, Boo S, Low YK, et al. Two-phase flow metering using a large Coriolis mass flow meter applied to ship fuel bunkering. Measurement + Control 2008;41:208-12.

[236] Mattar W. Coriolis metering in difficult industrial applications. Comput Control Eng 2003;14:44-5.

[237] Patten T, Dunphy K. Flow measurement in bitter cold: How to use Coriolis meters in cryogenic service. Chemical Engineering 2006;113:48-9. 
[238] De Jonge T, Patten T, Rivetti A, Serio L. Development of a mass flowmeter based on the Coriolis acceleration for liquid, supercritical and superfluid helium. The 19th International Cryogenic Engineering Conference, Grenoble, France: 2002, p. 64750 .

[239] Post IJH, Dirkes MC, Heger M, Bezemer R, van 't Leven J, Gulik T. Optimal flow and pressure management in machine perfusion systems for organ preservation. Ann Biomed Eng 2012;40:2698-707.

[240] Stevens J. Are Coriolis flowmeters: A universal technology? Control Engineering 2010;57:38-41. 